$\mathcal{G S}_{\text {https://doi.org/10.3765/sp.12.16 }}^{\text {Semantics \& Pragmatics Volume 12, Article 16, } 2019}$

This is an EARLY ACCESS version of

Frana, Ilaria \& Kyle Rawlins. 2019. Attitudes in discourse: Italian polar questions and the particle mica. Semantics and Pragmatics 12(16). 1-48. https: //doi.org/10.3765/sp.12.16.

This version will be replaced with the final typeset version in due course. Note that page numbers will change, so cite with caution. 
EARLY ACCESS

\title{
Attitudes in discourse: Italian polar questions and the particle mica $^{*}$
}

\author{
Ilaria Frana \\ University of Enna "Kore"
}

\author{
Kyle Rawlins \\ Johns Hopkins University
}

\begin{abstract}
This paper explores ways in which discourse participants convey an attitude about another discourse participant's conversational move. We examine the semantics/pragmatics of Italian positive and negative polar questions (building on the literature on biased questions) and propose the first fully compositional analysis of the Italian particle 'mica', appearing in negative polar questions and negative assertions. The core is that 'mica' is member of a family of presuppositional, epistemic 'common ground management' operators, leading to a new account of epistemic inferences in biased polar questions that relies on the presuppositional nature of these operators. We argue that 'mica' is a high-left-periphery particle that indicates a presupposed bias against a proposition being added to the common ground, anchored uniformly to the speaker and therefore not showing 'interrogative flip'. The paper develops connections between common-ground management operators and evidentials, arguing that interrogative flip (and lack thereof) is a phenomenon that should be studied for a wide variety of discourse particles.
\end{abstract}

Keywords: Polar questions, negation, bias, discourse particles, epistemic modality, evidentiality, interrogative flip

\section{Introduction}

This paper explores modal displacement at the level of discourse, where an agent conveys a mental attitude toward another agent's conversational move. We focus on polar questions (henceforth, PQs) in Italian, and the ways in which such questions convey 'biased' attitudes. For example, by uttering the PQ in (1), B conveys a prior bias in favor of the positive answer to the question: that at some point before A's utterance, B thought/assumed that A visited the South American country Peru.

* For discussion of this topic we are grateful to two anonymous reviewers and David Beaver for extensive written comments, audiences at Incontro di Grammatica Generativa 46, SuB 20, NELS 44 (where this work began as a poster presentation in 2013), UConn, UMass, and JHU, as well as Adriana Belletti, Valentina Bianchi, María Biezma, Justin Bledin, Daniel Goodhue, Vincenzo Moscati, Luigi Rizzi, Maribel Romero, Mengxi Yuan and Raffaella Zanuttini. 
A: Non sono mai stata in Sudamerica. ('I've never been to S. America')

B: Non eri andata in Peru l'anno scorso?

NEG were.2sg gone to Peru the.year last

'Didn't you go to Peru last year?'

If we take A's assertion in this case to signal their intent to add the content proposition "I have never been to South America" to the common ground, B's response - after the computation of the bias - conveys B's attitude towards A's conversational move. In particular, B is challenging A's attempt to add this proposition to the common ground on the basis of epistemic conflict: what A is claiming is in conflict with B's original belief. Building on the literature on the semantics/pragmatics of English PQs (Ladd (1981); Büring \& Gunlogson (2000); Romero \& Han (2004); a.o.), we provide the first detailed analysis of biases in Italian PQs and a novel account of the Italian particle mica at the semantics-pragmatics interface. ${ }^{1}$

The first part of the paper introduces the key data about mica and its place in the negative system of Italian. Mica is a negative marker deriving from a nominal minimizer - the Latin word micam ('crumble'). It appears in both assertions and PQs (Cinque 1976, Zanuttini 1997, Penello \& Pescarini 2008, Frana \& Rawlins 2016). ${ }^{2}$ In assertions, this particle indicates a denial, whereas in PQs, it indicates a prior expectation on the part of the speaker for the negative answer to the question, thus reversing the usual speaker's bias of negative PQs, we will label this phenomenon bias reversal. We then proceed to explore the pragmatics of English and Italian PQs and argue that, despite surface differences, there are deep analogies between them, thus motivating a parallel analysis.

Bias reversal is illustrated by the pair in (2)-(3) below. In (2), B's negative polar question (with plain sentential negation, non) conforms to what we already observed for (1); the question conveys a prior expectation for the positive answer (that A had been invited to the party) and its use is licensed by 'epistemic conflict': the content of A's claim provides evidence against B's pre-existing positive expectation. Adding the particle mica to B's question in this mini-dialogue leads to infelicity.

1 There is some controversy on how to characterize biases in PQs. Two types of 'biases' have been discussed: what Domaneschi et al. (2017) term the original speaker bias or original belief prior to the utterance, and the newly acquired belief or contextual evidence bias emerging from contextual evidence (see also Sudo (2013)'s distinction between epistemic and evidential bias). Both types of bias have been used to model the speaker's expectation for the most likely answer to the PQ. Ladd (1981) and Romero \& Han (2004) focus on the original speaker bias; Büring \& Gunlogson (2000) focus instead on the newly formed bias emerging from contextual evidence; van Rooy \& Safarova (2003) merge the two types of biases into one; see also Gunlogson (2001), Asher \& Reese (2005), AnderBois (2011), Gutzmann \& Miró (2011), Sudo (2013), Krifka (2017), Roelofsen \& Farkas (2015), Farkas \& Roelofsen (2017), Domaneschi et al. (2017), Goodhue (2018b) for further discussion of bias and types of biasing effects we do not consider here.

2 As noted by Cinque (1976), mica can also be used in negative imperatives, which we will set aside. 
The reverse holds for (3). Here, B's negative question with mica conveys that B had a prior expectation for the negative answer (that A would not be invited to the party); omitting mica in this case, would lead to infelicity. ${ }^{3}$ This question is also motivated by epistemic conflict: the content of A's claim provides evidence against B's pre-existing negative expectation.

(2) A: Tomorrow I am finally staying in.

B: Non eri stato (\#mica) invitato alla festa per Alex?

'Weren't you invited to the party for Alex?'

(3) A: I know that Alex hates me and tomorrow there's gonna be big drama.

B: Non sei \#(mica) stato invitato alla sua festa a sorpresa?

'You aren't invited to his surprise party, are you?' (roughly)

The second part of the paper develops an analysis of Italian biased questions by extending Romero \& Han (2004)/Romero (2014)'s analysis of biases in English PQs to Italian, though we will make substantial revisions to the core theory. With the toolbox for PQs in hand, we return to the account of mica, proposing mica is uniformly an epistemic common ground management operator that indicates an agent's beliefs about whether some proposition should be part of the common ground. This analysis therefore unifies mica with other common ground management operators that have been proposed to account for question bias and denials across languages; in particular, the operators VERUM and FALSUM (Romero \& Han 2004, Repp 2013, Romero 2014). We propose that mica is special in that it is an inherently subjective operator. VERUM and FALSUM mirror many documented evidential operators by reflecting the perspective of the speaker in unembedded assertions and of the hearer in questions, but mica does not shift its perspective in questions; thus it does not undergo what in the evidential literature is referred to as interrogative flip (Speas \& Tenny 2003). We argue that this feature of mica is responsible for its bias reversal effect in PQs. More broadly, our proposal contributes to a larger understanding of the typology of perspectival anchoring in epistemic operators.

3 Mica is subject to dialectal/regional variation. As discussed in Squartini (2017), there is a secondary use of mica in some dialects with a distinct intonation, which does not trigger 'bias reversal'; in these dialects, with the relevant intonation pattern, (2) is acceptable with mica. This secondary use is not accepted by all speakers of Italian: "It is in fact a regional phenomenon restricted to varieties of Italian, whose geographical boundaries are not clear yet, but in a preliminary delimitation, can be located in an area in the North-West of Italy, possibly centered in Lombardy and Northern Emilia" (Squartini 2017:12). In this paper, we will not consider this variety. For other aspects of variation in the use of mica across Italian dialects see also Garzonio \& Poletto (2009), Penello \& Pescarini (2008), and Visconti (2009) for a diachronic approach. 
Frana \& Rawlins

\section{Mica and negation in assertions}

We turn first to the behavior of mica in assertions. Italian uses a preverbal negative marker (non) to express sentential negation, as shown in the examples below.

\section{a. Gianni non ha telefonato. Gianni NEG has phoned. 'Gianni didn't call.'}

b. Non fa freddo a Roma. NEG does cold at Rome. 'It's not cold in Rome.'

The particle mica can appear as a discontinuous element of non, as in S's response in (5), or as an autonomous negative element (Cinque 1976) as in $S^{\prime}$, without any difference in interpretation. (What that interpretation is exactly, we return to in section 2.2).

A: Fa freddo fuori. 'it's cold outside.'

S: Non fa mica freddo. $\quad S^{\prime}$ : Mica fa freddo. NEG does MICA cold. MICA does cold.

'It's NOT cold.' (roughly)

Following Cinque (1976), Zanuttini (1997), we assume that autonomous mica is derived from discontinuous mica via movement: mica moves and takes the place of non, incorporating its negative meaning. As a discontinuous element of non, mica follows verbal elements (auxiliaries, modals, participles), but cannot precede the first one of them and it cannot occur after non-verbal elements that follow the verbal group (Cinque 1976). The spaces in the sentence below show where mica can occur in a sentence, the stars the places where it cannot occur:

$$
\begin{aligned}
& \text { Non * può _ essere _ stato _ vinto _ da quella schiappa *. } \\
& N^{*} * \text { can _ be _ been _ won _ by that fool } * \\
& \text { 'He cannot have been beaten by that fool.' } \\
& \text { (Cinque } 1976 \text { ex. 6) }
\end{aligned}
$$

We will adopt a version of Zanuttini's syntax for mica. Zanuttini (based on a range of evidence about negation in Romance) proposes an extended sequence of functional projections that includes two positions for negation. (Standard) Italian negation non is base-generated in the higher position, NegP-1, and mica is generated in the specifier of the lower position, NegP-2; see (b) in Figure 1. The surface structure of autonomous mica, illustrated in (a) in Figure 1, involves mica moving to Spec,NegP1 , and as a result, the head of that projection not being spelled out independently. The featural annotations in these trees are our own augmentation to Zanuttini's proposal. While these syntactic proposals do not settle what the LF of a mica sentence might be, they do suggest that, consistent with the interpretive evidence so far, autonomous and discontinuous mica should be treated in a similar fashion. 
Italian polar questions and 'mica'

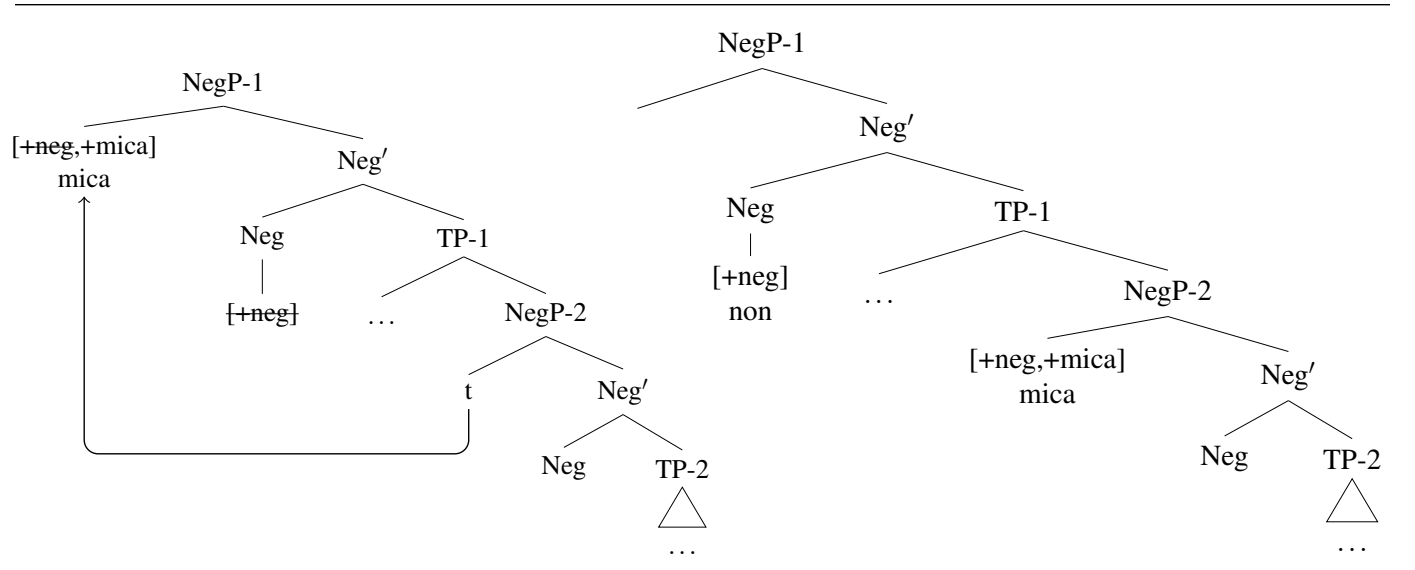
a. Autonomous mica, surface structure
b. Discontinuous mica, surface structure

Figure 1 Our implementation of Zanuttini's proposal

\subsection{Using mica in declaratives signals contrast/denial}

Unlike plain negation non, mica in declaratives requires a prior claim or salient expectation to deny (Cinque 1976). Compare the minimally different dialogues below, where the negated sentence with mica is marked in the first dialogue, but acceptable in the second. The difference is that in (8), A asks a question that signals he is wrongly assuming that S's sister is in a position of giving them a ride, i.e., she can drive, she has a car, etc. The implicit assumption is what is licensing mica here (same judgments for autonomous mica). ${ }^{4}$

NYC Party: S and A live in Amherst and want to go to a party in NYC.

A: How are we going to get there?

S: Mia sorella non ha (\#mica) la macchina questo fine settimana,

My sister NEG has (\#MICA) the car this weekend altrimenti ci avrebbe accompagnato volentieri. otherwise us would.have accompanied gladly

'My sister doesn't have (\#MICA) the car this weekend, otherwise she would have gladly given us a ride.

(8) A: How are we going to get there? Can your sister give us a ride?

$\mathrm{S}$ : Mia sorella non ha (mica) la macchina. Ha 13 anni!

My sister NEG has (MICA) the car. Have.3sg 13 years!

'My sister DOESN'T have a car, she is 13!'

4 In the variety of Italian we focus the choice between autonomous and discontinuous mica in all the examples provided is irrelevant to the interpretation. 
Unlike non, which can be used to assert new negative propositions, mica in declaratives seems to be limited to denials. It is known since Horn (1985) that the essential function of a denial is to object to a previous utterance on any grounds whatever, including its conventional or conversational implicata, its morphology, its style or register, or even its phonetic realization. We identify three types of context that license the use of mica in assertions: rectification of an utterance - where mica is used to object to a previous utterance on any ground whatever; rectification of implied content, where mica is used to deny a proposition that the speaker is attributing to the addressee, even when the addressee has not uttered anything to that effect; and self-rectification - where mica is used by the speaker to deny one of her own prior expectations. ${ }^{5}$ Some examples are included below, where $p$ refers to the propositional content of $\alpha$ in "(non...) mica $\alpha$ "; we will call this the prejacent.

\section{Rectification of an utterance}

a. Propositional Denial (A's utterance asserts $p$ )

A: Mario cried when his girlfriend broke up with him.

S: Non é vero. M. mica ha pianto quando lei l'ha lasciato. NEG is true. M. MICA has cried when she him-has left.

'That's not true. Mario DIDN'T cry when she left him!'

b. Presuppositional Denial (A's utterance presupposes $p$ )

A: How's your dog?

S: Non ho mica un cane io. NEG have.1sg MICA a dog I

'I don't have a dog!'

c. Implicature Denial (A's utterance implicates $p$ )

A: Gianna solved some problems. [implicates: not all of them]

S: Gianna non ha mica risolto QUALCHE problema, G. NEG have.1sg MICA solved SOME problem, li ha risolti tutti. them have.3sg solved all

'G. did not solve SOME problems. She solved them ALL!'

(10) Rectification of Implied Content (S infers that $p$ is assumed by A)

Context: $\mathrm{S}$ sees A pouring milk into a dish for $\mathrm{S}$ 's cat.

S: Guarda che il latte non fa mica bene al gatto. look that the milk NEG does MICA good to.the cat.

'Look, milk is NOT good for cats!'

5 Self-rectification evokes the use of 'mirative' particles in evidential languages (DeLancey 1997). See Squartini (2017) for a descriptive discussion of connections between mica and mirativity. However, mica cannot always be described as mirative, e.g. in PQs used for polite requests. 
Italian polar questions and 'mica'

(11) Self-rectification (S signals prior expectation of $p /$ that $\neg p$ is surprising)

Context: $S$ thinks it'll be cold, but finds it warmer than expected.

S: Ah! Non fa mica così freddo.

Oh! NEG does MICA so cold.

'Oh! It's NOT so cold after all.'

There are two take-home points from this data. First, mica in declaratives occurs in a subset of the environments where non could or does occur - in all of the above examples, plain negation would also be acceptable. Second, mica is not just for surface denials: it can deny a proposition that has never been expressed linguistically, nor presupposed or implied by a previous utterance, including one that has been simply inferred as a belief of another participant.

\subsection{Previous proposal: mica as presuppositional in assertions}

Cinque (1976) (see also Zanuttini 1997, Penello \& Pescarini 2008) suggests that mica in declaratives is a presupposition trigger: a sentence of the form (non) mica $p$ asserts that $\neg p$ and presupposes that $p$ was expected. We sketch a particular version of this in (12):

$$
\begin{array}{ll}
\text { a. } & \llbracket \text { NON } \alpha \rrbracket^{c}=\neg \llbracket \alpha \rrbracket^{c} \\
\text { b. } & \llbracket \text { MICA } \alpha \rrbracket^{c}=\llbracket \text { NON MICA } \alpha \rrbracket^{c}=\neg \llbracket \alpha \rrbracket^{c} \\
& \text { Defined in } c \text { only if } \llbracket \alpha \rrbracket^{c} \text { is assumed by some participant in } c .
\end{array}
$$

This directly captures the distributional facts for declaratives from section 2.1. First, it straightforwardly predicts that mica-sentences will be good in a subset of the cases where regular negative sentences would be good, because the presupposition introduced in (12b) as a definedness condition leads to mica-declaratives being defined in a subset of the contexts where negative sentences are defined, and having the same truth-conditions when defined. The proposal also captures the contextual licensing conditions for mica: the presupposition is intended to cover cases where any participant (including the speaker) said or implied or acted as if they believed $\llbracket \alpha \rrbracket^{c}$. A speaker being aware of their own prior assumptions, even if they haven't communicated them, is just another special case.

Despite capturing many of the distributional facts we have shown so far, there are some facts that do not obviously follow from this analysis (at least as we have stated it). First, as we will discuss in section 2.3, mica must scope higher than other operators in the sentence (e.g. modals). Second, in section 3 we show that mica in polar questions induces what we label bias reversal, a pattern of data that will occupy much of the rest of the paper. 
Frana \& Rawlins

\subsection{Mica must scope high}

As Penello \& Pescarini (2008) discuss, the presence of mica interacts with other scopal elements. Where regular negation is ambiguously scoped with respect to the deontic universal modal dovere, as shown in (13), mica-negation must scope above, as shown by the fact that (14)-b is not a possible reading. ${ }^{6}$

Non devi guidare.

NEG must.2sg drive

a. 'You must not drive.'

b. 'You don't have to drive.'

Mica devi guidare.

MicA must.2sg drive

a. \#'You must not drive.'

b. 'You don't have to drive.'

(\#MUST $\gg \mathrm{NEG)}$

$(\mathrm{NEG} \gg \mathrm{MUST})$

Penello \& Pescarini (2008)'s observation can be reproduced with existential deontics, as well. In this case though, the scope of the modal with respect to negation is fixed. Specifically, when negation is placed above the modal, the only possible interpretation is the one following surface scope (NEG $\gg$ CAN: "It is not the case that you can..."). Conversely, when regular negation is placed below the modal the only possible interpretation is CAN $\gg$ NEG ("It is allowed to not..." = "you don't have to..."). The interesting fact is that mica can only be be used in the first sentence type, where negation takes wide scope over the modal, as illustrated below. This observation is not about felicity in particular contexts, but rather is general: there is no possible scenario that would rescue the acceptability of mica in the second example (same judgments for autonomous mica).

A: I was thinking of wearing a tie at the party.

S: Non puoi (mica) indossare la cravatta. Il party è casual. NEG can.2sg (MICA) wear the tie. The party is casual. 'You can't wear a tie.' (only NEG $\gg$ CAN, mica ok)

$\mathrm{S}^{\prime}$ : Puoi non indossare (*mica) la cravatta. Il party è casual. can.2sg NEG wear (*MICA) the tie. The party is casual. 'You don't have to wear a tie.' (only CAN $\gg$ NEG, *mica)

6 In the variety of Italian we investigate in the present paper (Southern) the same judgment holds for discontinuous mica. Instead, Penello \& Pescarini (2008) report that in the North-Eastern dialects (Veneto region) discontinuous mica has both interpretations in (13). We leave this point of variation for future investigation. The data point in (13)-(14) is due to Penello \& Pescarini (2008), but the characterization in terms of scope is ours. 
Italian polar questions and 'mica'

An analogous contrast can be replicated with epistemic modals. As in the case of the existential deontics, existential epistemic modals have fixed scope with respect to negation in Italian. When the modal potrebbe (roughly, "could" or "might") precedes negation, the only available reading is the one following from surface scope (Might $\gg$ NEG). This is shown in the context below, where Sherlock's first reply to Watson can only mean that the murderer might not be (= does not have to be) Mr. Purple. Replacing ordinary negation with mica in this particular configuration, leads to ungrammaticality (same judgments with discontinuous mica). On the other hand, if Sherlock intends to express a strong denial of Watson's claim, namely that the murderer can't be Mr. Purple (NEG $\gg$ MAY), this can be rendered by placing negation above the possibility modal può (roughly, "can" or "may"). This configuration is grammatical with both regular negation and mica and both versions of the sentence obligatorily have the reading following from surface scope (which in this case is NEG $\gg$ MODAL). ${ }^{7}$

Context: Sherlock and Watson:

W: L'assassino potrebbe essere Mr. Purple! Andiamo a interrogarlo! 'The murderer might be Mr. Purple! Let's interrogate him'

$\mathrm{S}$ : Aspetta, l'assassino potrebbe non/*mica essere Mr. P. Wait, the.murderer might NEG/*MICA be Mr. P. 'Wait, the murderer might not be Mr. Purple!' (only Might $\gg$ NEG, *mica)

S': No, l'assassino non/mica può essere Mr. Purple. no the.murderer NEG/MICA can be Mr. Purple. 'It's not the case that the murderer may be Mr. Purple!'

(only NEG $\gg$ MAY, mica ok)

The last piece of scopal evidence comes from conditionals. As shown below, mica cannot occur in the antecedent of a conditional (17), while it can occur in the consequent (18). We take this to be evidence that mica at LF must be high enough in the left periphery that it does not embed in (conditional) adjuncts headed by se ('if'; see Iatridou 1991, Haegeman 2003 et seq for discussions of the ways in which the internal syntax of conditional adjuncts can be truncated relative to root CPs). ${ }^{8}$

$$
\text { A: It'll rain tomorrow. }
$$

7 The sentences L'assassino non/mica potrebbe essere (/mica) Mr. Purple are also grammatical, but dispreferred to the stronger denial made by using può instead of potrebbe.

8 An alternative explanation for why mica is ruled out in the antecedent of conditionals follows from the restrictor analysis of conditionals (Lewis 1975, Kratzer 1986, Heim 1982). Under this view, if-clauses restrict the domain of a (possibly covert) modal, thus effectively trapping mica under the scope of a modal; a configuration which, as we already observed, leads to ungrammaticality. 
S: Se domani non/*mica piove (/*mica), possiamo andare al mare.

'If it does not rain tomorrow, we can go to the beach.'

A: Tomorrow we'll go to the beach.

S: Se domani piove, non/mica possiamo (/mica) andare al mare.

'If it rains tomorrow, we can't go to the beach.'

All together the data suggest that mica-negation must scope high at LF, even higher than epistemic modals; if it must appear at LF high in the left periphery, both the scopal data and the conditional data fall out straightforwardly. This contrasts with the scopal possibilities for non, which can be substantially lower. These facts aren't incompatible with Cinque's presuppositional proposal, but they also aren't explained by it: why should negation with mica scope so much higher than regular negation?

In summary, mica in assertions has three key properties. First, it is felicitous in a subset of cases where non is: those where the complement proposition of mica (the prejacent) is assumed or taken for granted by some discourse participant. Second, this isn't just a 'surface' denial: mica can be used to deny not just linguistic claims, but propositions that have not been previously expressed, nor presupposed or implicated. Third, mica in declarative clauses scopes high, at least high enough to necessarily outscope epistemic modals. ${ }^{9}$ In the next section, we will characterize the felicity conditions of mica in polar questions and introduce the phenomenon of bias reversal.

\section{Mica in Polar Questions and bias reversal}

\subsection{Biases in English polar questions}

A polar question (PQ; sometimes called a 'Yes/No' question) is standardly treated as a question that asks whether a given proposition is true or not (Hamblin 1973, Karttunen 1977, Groenendijk \& Stokhof 1984, Roberts 1996, 2012 a.m.o.). Despite this simple idea, PQs have proven to be quite complicated in their pragmatic details (Borkin 1971, Bolinger 1978, Ladusaw 1979, Ladd 1981 a.m.o.). The examples below illustrate five distinct ways of raising a polar 'issue' in English. ${ }^{10}$ These alternatives vary on the basis of the presence/absence and position of negation (High vs. Low negation) as well as extra emphatic marking; the ' $\mathrm{V}$ ' in 'V-PPQ' stands for what has been termed 'verum' marking or 'verum focus' (Höhle 1992, Romero \& Han 2004, Gutzmann \& Miró 2011 a.o.) rendered by intonational marking on the

9 This applies to the use of mica in root clauses. We mostly set aside data where mica is embedded under, for example, attitude verbs.

10 See Gunlogson (2001), Malamud \& Stephenson (2015), Farkas \& Roelofsen (2017) for work that considers an even wider range of polar-like moves. 
Italian polar questions and 'mica'

main verb or an epistemic adverb like really. ${ }^{11}$ Although they raise the same issue (i.e., whether or not the addressee is married), the PQs below each have different felicity conditions and cannot be used interchangeably by native speakers.
a. Are you married?
Positive Polar Question (PPQ)
b. Are you MARRIED?/Are you really married?
(V-PPQ)
c. Aren't you married?
(HiNPQ)
d. Are you not married? Have those dating sites not been working for you? Try ours!
(LowNPQ)
e. Are you NOT married?/Are you really not married? (V-LowNPQ)

As discussed extensively in the literature on PQs (see e.g. Ladd 1981, Büring \& Gunlogson 2000, Romero \& Han 2004, van Rooy \& Safarova 2003, AnderBois 2011, Sudo 2013, Goodhue 2018b) marked forms of PQs can be used to request confirmation for ('double-check') both the speaker's prior bias, and what we will call evidential bias - that is, a proposition implied by contextual evidence. In the remaining of this section, we will briefly review the felicity conditions of PPQs and HiNPQs (we return to LowNPQs in 4.1).

PPQs without polarity focus are seemingly 'neutral' with respect to the context, as they can be felicitously used in interview scenarios, where the speaker can have no prior expectations regarding the resolution and the contextual evidence may as well be absent:

$$
\text { Do you have a college degree? }
$$

However, as Büring \& Gunlogson (2000) first pointed out, although unbiased in a certain sense, English PPQs are not fully neutral with respect to contextual evidence, and they are subject to the relatively weak evidence condition (21).

Evidence condition on PPQs: A PPQ of the form " $p$ ?" is felicitous only if there is no compelling evidence against $p$, i.e. either there is no evidence or there is evidence for $p$.

The two scenarios below from Büring \& Gunlogson (2000) illustrate this point.

(22) Neutral scenario (no prior bias, neutral evidence): $\mathrm{S}$ and A are talking long-distance on the phone.

S: What's the weather like out there? Is it raining?/Is it sunny?

11 Following Romero \& Han (2004), we assume that this use of really is distinct from the intensifier, as well as the readings really obtains when embedded. 
Non-neutral scenario (no prior bias, non-neutral evidence) A enters S's windowless computer room wearing a dripping wet raincoat. (Contextual evidence for it is raining/it is not sunny).

S: What's the weather like out there? Is it raining?/\#Is it sunny?

Thus, PPQs are sensitive to the available evidence in the context. However, they do not seem to require a prior bias on the part of the speaker.

Let's now turn to PPQs with VERUM focus or epistemic really (V-PPQs) and negative PQs with preposed (high) negation (HiNPQs). Unlike regular PPQs, these PQs are not felicitous in neutral scenarios, where both the speaker and the context lack prior expectations or evidence w.r.t. the resolution of the question:

Neutral scenario (no prior bias, neutral evidence): $\mathrm{S}$ and $\mathrm{H}$ are talking about Alex's party for the first time.

S: Are you going to Alex's party?

S: \#Are you really going to Alex's party?/Are you GOING to Alex's party?

S: \#Aren't you going to Alex's party?

Instead, V-PPQs and HiNPQs are felicitous in contradiction scenarios, i.e., scenarios in which contextual evidence seemingly contradicts the speaker's prior expectation. More specifically, V-PPQs are felicitous in cases where the speaker had a prior expectation for the negative answer to the question (negative prior bias) and the contextual evidence seemingly contradicts that expectation. HiNPQs, on the other hand, are felicitous in cases where the speaker had a prior expectation for the positive answer to the question (positive prior bias) and the contextual evidence seemingly contradicts that expectation. The contrast is brought up by the two contexts below, which manipulate the polarity of the expectation/evidence.

(25) Contradiction scenario v1 (S expected $\neg p$, evidence for $p$ ): Alex is throwing a party and invited us both. You and Alex hate each other and I expect you would not attend the party. While we are on the phone, you say: "I am looking forward to seeing you at the party". I ask you:

S: Are you really going to Alex's party?/Are you GOING to Alex's party?

S: \#Aren't you going to Alex's party?

(26) Contradiction scenario v. 2 (S expected $p$, evidence for $\neg p$ ): Alex is throwing a party and invited us both. You and Alex are good friends and I expect you would attend the party. While we are on the phone, you inform me that you'll be out of town on the date of the party. I ask you:

S: \#Are you really going to Alex's party?/\# Are you GOING to A.'s party?

S: Aren't you going to Alex's party? 
Italian polar questions and 'mica'

\begin{tabular}{|l|l|l|}
\hline Type of polar question & $\begin{array}{l}\text { speaker's } \\
\text { prior bias }\end{array}$ & $\begin{array}{l}\text { contextual evidence } \\
\text { (H's implied bias) }\end{array}$ \\
\hline PPQ: Are you married? & can be absent & $p$ or absent \\
\hline $\begin{array}{c}\text { V-PPQ: Are you MARRIED? } \\
\text { Are you really married? }\end{array}$ & $\neg p$ & $p$ \\
\hline HiNPQ: Aren't you married? & $p$ & $\neg p$ or absent \\
\hline
\end{tabular}

Table 1 Summary of English polar question and bias types

Outside of contradiction scenarios, HiNPQs can also be used in the absence of contextual evidence in order to make a suggestion, as first pointed out by Ladd (1981) with the famous example in (27). In this example, Kat does have some prior expectation that this restaurant exists, but in absence of contextual evidence, she is posing the question to double-check that her expectation is correct.

\section{Ladd's 1981 suggestion scenario (S expected $p$, neutral evidence)}

Kathleen and Jeff just come from Chicago on the Greyhound bus to visit Bob in Ithaca.

Bob: You guys must be starving. You want to get something to eat?

Kat: Yeah, isn't there a vegetarian restaurant around here? Moosewood, or something like that?

The key types of biased polar questions are summarized in Table $1 .^{12}$

With this picture in hand, we can turn to positive and negative PQs in Italian and ask a similar question: what expectations involving the speaker and the hearer can be conveyed by different types of PQs?

\subsection{Biases in Italian Polar Questions}

Italian PQs differ from English in at least two respects: there is no marking beyond intonation for PQs (which we signal with punctuation), and there is only one possible surface position for regular negation. ${ }^{13}$ However, we will show that there are sub-

12 This table is not intended as exhaustive: we have not dealt with either LowNPQs, or with other biasing mechanisms such as tag questions or minimizers. Moreover, as it will emerge, simply describing the polarity (positive vs. negative) of the biases does not give a complete characterization of the felicity conditions of biased questions, even from a descriptive point of view. The felicitous use of PQs may be further restricted by constraints regarding the type of available evidence (direct/indirect), which we are not addressing here.

13 The exact intonation that marks questions in Italian is complicated and dialect/region-specific; see D'Imperio (2002), Grice et al. (2005) for an overview. Very roughly, in Northern dialects it is a final 
Frana \& Rawlins

stantial similarities. Just as in English, Italian PPQs are acceptable in interview-type scenarios, whereas NPQs and V-PPQs are not. ${ }^{14}$

Interview context (out of the blue)

a. (\#Veramente) $\mathrm{E}$ laureato?

(\#Really) be.3sg graduate?

'Do you (\#really) have a college degree?'

b. \#Non è laureato?

NEG be.3sg graduate?

'Don't you have a college degree?'

(PPQ/\# V-PPQ)

Also parallel to the English facts, Italian PPQs are subject to Büring and Gunlogson's evidence condition, whereas NPQs and V-PPQs are felicitous in contradiction scenarios. In particular, NPQs are felicitous in scenarios where the speaker had a prior bias for the positive answer to the question and contextual evidence seemingly contradicts that bias, the opposite holds for V-PPQs.

The two scenarios below, introduced in Frana \& Rawlins (2016) illustrate the contrast between Italian PPQs and NPQs. In Good Manners v. 1, the PPQ is infelicitous, because the context violates the evidence condition (by asking for food, Miles provides evidence against the proposition that he has eaten already), whereas the NPQ is felicitous because the scenario meets the contextual requirements: (prior) positive bias (Clara expected Miles to have eaten already) and negative contextual evidence (Miles' behavior provides evidence against Clara's pre-existing expectation). In Good Manners v. 2, the opposite holds. Here, the PPQ is felicitous because the context satisfies the evidence condition (M.'s behavior provides evidence for the proposition that he has eaten already), whereas the NPQ is marked because the context makes it clear that the speaker did not have a (prior) positive bias (C. invited M. for dinner, thus she expected him to not have eaten already).

Contradiction: Good Manners v. 1 (S expected $p$, evidence for $\neg p$ )

Clara invites Miles for drinks and tells him to come after dinner. When he gets there, Miles asks if she has any food. Clara asks:
a. \#Hai già mangiato?
have.2sg already eaten?
'Did you eat already?'

rise, and in Southern dialects, it is a rise leading to the nuclear pitch accent. In the Southern Italian variety that this paper focuses on, given our preliminary fieldwork, mica receives the nuclear accent in most circumstances, so there may be a regular interaction in this variety between the position of mica and the question contour. We will not investigate the intonational properties of mica here, leaving it for future work.

14 In Italian, the third person is used to address interlocutors in formal situations. 
Italian polar questions and 'mica'

b. Non hai già mangiato? (NPQ)

NEG have.2sg already eaten?

'Didn't you eat already?'

(30) Contradiction: Good Manners v. 2 (S expected $\neg p$, evidence for $p$ )

Clara invites Miles for dinner and makes clear that she will prepare her best dishes. At dinner Miles barely touches any food. Clara asks him:

a. Hai già mangiato?

(PPQ)

b. \#Non hai già mangiato?

(NPQ)

Furthermore, Italian NPQs can also be used in Ladd's suggestion scenarios.

Suggestion context variant: (S expected $p$, neutral contextual evidence)

Clara has just arrived to visit her friend Luigi in Napoli.

L: You must be starving, shall we we get something to eat?

$\mathrm{C}$ : Si, certo. Non c'era una pizzeria buona da queste parti? Da Yes, sure. NEG there.was a pizzeria good in this vicinity? By Michele, o un nome del genere?

Michele or a name of.the kind

'Yes, sure. Wasn't there a good pizzeria around here? Michele's or something like that?

So far, despite syntactic differences, the Italian PQ system appears to parallel the parts of the English PQ system under consideration. In the next section, we will return to mica and introduce the phenomenon of bias reversal, something quite different to anything seen in English.

\subsection{Mica in Polar Questions induces Bias Reversal}

As anticipated, mica can also occur in PQs; though it cannot appear in constituent questions (Cinque 1976). In PQs, mica has the same syntactic distribution as in declaratives, as shown in (32) for the discontinuous use:

$$
\begin{aligned}
& \text { Non * può _ essere _ stato _ vinto _ da quella schiappa *? } \\
& \text { NEG }^{*} \text { can _ be _ been _ won _ by that fool * }
\end{aligned}
$$

'He cannot have been beaten by that fool, can he?'(after Cinque 1976 ex. 6)

Frana \& Rawlins (2016) demonstrate that Italian NPQs are felicitous in scenarios where the speaker holds a prior positive bias, i.e. a prior bias for the positive answer to the question (with conflicting contextual evidence, as in contradiction scenarios, or neutral evidence, as in suggestion scenarios). However, when mica is added to an 
NPQ, it does not simply reinforce that positive bias (which we might expect from the assertion case), but reverses it - a mica-PQ is compatible with a negative prior bias, i.e. it is felicitous in contexts where the speaker holds a prior expectation for the negative answer to the question (and the context provides counter-evidence). Thus, unlike in assertions, regular negation and mica-negation in PQs are in complementary distribution. The mica examples in our 'good manners' scenarios illustrate this bias reversal effect. As before, the alternative word order (discontinuous mica) has equivalent acceptability conditions. ${ }^{15}$

\section{Context: good manners v. 1 (S expected $p$, evidence for $\neg p$ )}

Clara invites Miles for drinks late in the evening and tells him to come after dinner. When he gets there, M. asks if she has any food. C asks him:

S: Non hai già mangiato? ('Didn't you eat already?')

S: \#Mica hai già mangiato?

(Mica-PQ autonomous)

MICA have.2sg already eaten?

S: \#Non hai mica già mangiato?

NEG have.2sg MICA already eaten ${ }^{16}$

(Mica-PQ discontinuous)

\section{Context: good manners v. 2 (S expected $\neg p$, evidence for $p$ )}

Clara invites Miles for dinner and makes clear to him that she will prepare her best dishes. When he gets there, M. barely touches any food. C. asks:

S: \#Non hai già mangiato?

(NPQ)

$\mathrm{S}$ : Mica hai già mangiato?

(Mica-PQ autonomous)

S: Non hai mica già mangiato?

(Mica-PQ discontinuous)

In these scenarios Mica-PQs pattern with PPQs: they are both compatible with the speaker expectation of the negative resolution, and evidence for the positive resolution. However, Mica-PQs are not just compatible with this bias, but require it. Thus, in contrast to PPQs, they are inappropriate in neutral interview contexts. This completes the paradigm introduced earlier in (28):

Interview context (out of the blue)

\section{S: \#Mica è laureato? (Mica-PQ) MICA be.3sg graduate?}

Mica-PQs are also distinct from V-PPQs, in both English and Italian. Just like V-PPQs, Mica-PQs mandatorily convey the speaker's prior negative bias and are

15 From now on, we will stop bringing up this alternative word order, which has has equivalent meaning as the autonomous mica order in the variety we focus on.

16 English has no general translational equivalent of mica, and we therefore will not always provide a full translation. Paraphrases that come quite close for this particular example would be: oh no, you didn't eat, did you? and you were not supposed to eat...did you?, but these do not generalize. 
infelicitous in interview-type contexts. However, these two PQs do not have the same felicity conditions. The Italian V-PPQ Veramente hai giá mangiato? (just like its English counterpart Did you really eat already?) is infelicitous in Good Manners v. 2, despite the fact that the scenario satisfies both biases (see Table 1) - we will return to an explanation of this contrast in $\S 6$. Moreover, while V-PPQs are limited to contradiction scenarios, a Mica-PQ - just like an NPQ - can be used in absence of counter-evidence. For instance, nothing in the context described in (36) counts as evidence in favor of the positive proposition ("that you told your mother that you were coming over"), yet mica is felicitous.

(36) Paranoid Scenario (S expected $\neg p$, neutral evidence): Your mother doesn’t want you to hang out with me. We still want to hang out, but to avoid trouble I asked you to not tell her when you come over. As I open the door to you, I get a bit paranoid and I ask you:
S: Mica hai detto a tua madre che venivi qui?
MICA have.2sg said to your mother that come.2sg here
'You didn't tell your mother that you were coming over, right?'

Another typical use of Mica-PQs in the absence of contextual evidence is found in polite requests, where intuitively the speaker signals their prior bias for a negative answer in order to take some weight off the hearer's shoulders, by freeing them from fulfilling the request (Cinque 1976, Manzotti \& Rigamonti 1991: p. 284). In these cases, mica can be paraphrased with Italian per caso or its English equivalent by any chance.

$$
\begin{aligned}
& \text { Mica sai la password del computer di Mary? } \\
& \text { MicA know.3sg the password of.the computer of Mary? }
\end{aligned}
$$

'By any chance, do you know Mary's computer password?'

From these examples we conclude that mica PQs can be used in scenarios with neutral contextual evidence, as long as the context satisfies the other contextual parameter, namely that the speaker had a prior expectation for the negative answer to the question (or pretends to have it, as in the case of polite requests). Table 2 summarizes the phenomenon of bias reversal.

One last data clarification point before leaving our data section on PQs: while many of the mica examples so far have expressed the speaker's disappointment (or some kind of bouletic modality), and this is a common function, this is not necessary. For example, it is absent from the incredulous reply in (38). 
Frana \& Rawlins

\begin{tabular}{|c|c|c|c|}
\hline & Type of polar question & $\begin{array}{l}\text { speaker's } \\
\text { prior bias }\end{array}$ & $\begin{array}{l}\text { contextual evidence } \\
\text { (H's implied bias) }\end{array}$ \\
\hline NPQ: & Non hai mangiato? & $p$ & $\neg p$ (or absent) \\
\hline Mica-PQ & $\begin{array}{l}\text { Mica hai mangiato? } \\
\text { Non hai mica mangiato? }\end{array}$ & $\neg p$ & $p$ (or absent) \\
\hline
\end{tabular}

Table 2 Bias Reversal with mica in contradiction scenarios:

Context: Lottery (S expects $\neg p$, evidence for $p$ )

Mario returns home holding a lottery ticket in one hand and a bottle of champagne in the other.

S: Mica hai vinto la lotteria???

MICA have.2sg won the lottery?

'Did you win the lottery???' (incredulous)

Similarly, while one common use is to express surprise, this is again not necessary, as shown by polite requests such as (37) above.

\subsection{Summary: Mica in declaratives vs. mica in PQs}

To conclude the description, we want an analysis of Italian PQs and mica that derives:

i. The distributional facts: mica in assertions is felicitous in a subset of the cases where non is. Mica-PQs and NPQs are in complementary distribution.

ii. The scopal facts: a modal cannot outscope mica at Logical Form and mica does not embed in the antecedent of conditionals.

iii. The felicity conditions: assertions of the form (non) mica $\alpha$. are felicitous in contexts in which the proposition expressed by $\alpha$ is assumed by some participants of the context. Question of the form (non) mica $\alpha$ ? are felicitous when the speaker had a prior (to the exchange) bias for the negative answer to the question.

iv. The phenomenon of bias reversal: With respect to the speaker's prior bias, Mica-PQs and NPQs have opposite polarity.

In order to address these points we need to first understand how biases work in PQs. This will be the topic of the next several sections, starting with English. 
Italian polar questions and 'mica'

\section{The scope of negation and Negative Polar Questions}

We will review evidence in $\$ 4.1$ that English NPQs with high/preposed negation (HiNPQs) and NPQs with low/non-preposed negation (LowNPQs) have slightly different felicity conditions (Büring \& Gunlogson (2000), Romero \& Han (2004), a.o.). Given that Italian, as we have discussed, has only one surface position for non, this raises the question of whether Italian should receive a different analysis of NPQs than English. To address this, we introduce the data on inner vs. outer negation readings, first discussed in Ladd (1981), and then examine comparable data in Italian. The main finding of this section is that Italian NPQs also have inner and outer negation readings.

\subsection{LowNPQs vs. HiNPQs}

The now-classic puzzle of positive vs. negative questions is that on standard accounts, the positive and negative forms of the questions are denotationally identical. For example, on Hamblin's (1973) proposal, the semantic content of a question is described as the set of propositions corresponding to possible (complete) answers, which for PQs are constructed from a proposition by simply taking the positive and negative version of that proposition:

$$
\begin{array}{ll}
\text { a. } & \llbracket \text { whether } p \rrbracket=\{p, \neg p\} \\
\text { b. } & \llbracket \text { whether } \neg p \rrbracket=\{\neg p, \neg \neg p\}=\{p, \neg p\} \\
\text { c. } & \text { Therefore, } \llbracket \text { whether } p \rrbracket=\llbracket \text { whether } \neg p \rrbracket
\end{array}
$$

Setting aside V-PPQs, where the difference in felicity conditions may follow from the presence of (VERUM) focus and/or (possibly covert) epistemic particles such as really, the truly puzzling contrast is the difference in felicity conditions between PPQs and NPQs, with only the latter leading to mandatorily biased interpretations.

However, a closer look at the data reveals that the standard semantic analysis of PQs may salvageable (from this puzzle at least), and that the observed difference in felicity conditions between PPQs and NPQs may rely on a special type of negation. We initially observed that, in English, NPQs can be realized with 'preposed'/high negation and non-preposed/low negation:

$$
\text { a. Doesn't this bus stop at the mall? }
$$

b. Does this bus not stop at the mall?

(LowNPQ)

So far, we have ignored this distinction in the position of negation and focused only on HiNPQs. However, the position of negation in English PQs correlates with certain interpretive differences, including the 'strength' of the speaker's prior bias. As shown by Romero \& Han (2004), HiNPQs obligatorily convey the prior positive 


\begin{tabular}{|c|c|c|c|}
\hline & Type of polar question & $\begin{array}{l}\text { speaker's } \\
\text { prior bias }\end{array}$ & $\begin{array}{l}\text { contextual evidence } \\
\text { (H's implied bias) }\end{array}$ \\
\hline PPQ: & Are you married? & can be absent & $p$ (or absent) \\
\hline V-PPQ: & $\begin{array}{l}\text { Are you MARRIED? } \\
\text { Are you really married? }\end{array}$ & $\neg p$ & $p$ \\
\hline HiNPQ: & Aren't you hungry? & $p$ & $\neg p$ (absent in suggestions) \\
\hline \multicolumn{2}{|c|}{ LowNPQ: Is she not coming either? } & can be absent & $\neg p$ (or absent) \\
\hline
\end{tabular}

Table 3 Summary of English polar question and bias types

bias, whereas LowNPQs do not necessarily convey such bias. Hence, the latter, but not the former, are felicitous in contexts where the speaker had no prior expectation regarding the answer to the PQ. The contrast is illustrated by the example below from Romero \& Han (2004). In the scenario the speaker has no prior bias for either answer to the PQ, and only the LowNPQ is felicitous. ${ }^{17}$

\section{Unbiased context: Rosa Montero}

$\mathrm{S}$ interviews A on TV about Rosa Montero.

A: Mrs. Rosa Montero's writing career is closely related to the political episodes that Spain has lived through since 1936. There were times when she simultaneously worked on prose and poetry, but there were other times full of journalistic prose and completely devoid of poetry.

S: Please tell us more about those poetic gaps, and about what exactly caused them. For example,

$S^{\prime}$ : Did she not write poetry in the 70s? And, if she didn't, why not?

$S^{\prime \prime}$ : \#Didn't she write (some/any) poetry in the 70s? And, if she didn't, why not?

This data leads to the updated picture of English PQs in Table 3. PPQs and LowNPQs do not differ with respect to the first parameter (speaker's prior bias), and both of them are subject to an evidence condition matching the respective polarity (Büring \& Gunlogson 2000). The cases that stand out are V-PPQs and HiNPQs. One could easily take it that polarity focus, or the presence of epistemic particles such as really, would have an impact on the compositional semantics of the PQ, but what is special about preposed negation? Outside of questions, the syntactic position of negation (high vs. low) has been shown to have several consequences

17 Note that focusing negation or adding an overt really will change these judgments. This is because we would turn a LowNPQ into a V-LowNPQ, which has a different semantics/pragmatic and consequently different felicity conditions. 
at the semantics/pragmatics of the sentences in which it occurs (Ladusaw 1979, Szabolcsi 2004, Schwarz \& Bhatt 2006, Romero 2014), most famously licensing of polarity items. Polarity items have been described as having a disambiguating effect that correlates with the scope of negation, between what have been termed inner and outer readings; this will be the topic of the next section.

\subsection{Inner vs. Outer negation readings}

As already noted, NPQs sound very natural in contradiction scenarios. These are cases in which the speaker had a previous expectation for the answer to the question (e.g. bias for $p$ ) and the context, or the addressee, is providing partial evidence against it. When faced with this type of epistemic conflict, the speaker might decide to ask an NPQ with one of these two intentions in mind: he or she may intend to confirm, or "double-check", their (positive) prior expectation for $p$ (outer negation reading) or to double-check the (new) implied proposition that $\neg p$ (inner negation reading; see Ladd 1981, Büring \& Gunlogson 2000, Romero \& Han 2004). The example below brings out the two readings intuitively. In both cases, the polarity of the prior bias is positive. It is just the proposition that gets 'double-checked' which changes: a prior bias for $p$ vs. a (new) implied inference that $\neg p$ (where $p=$ the bus stops at the Hampshire Mall).

\section{Context: Hampshire Mall (S expected $p$, evidence for $\neg p$ )}

$\mathrm{S}$ wants to go to the Hampshire Mall and has been told that the B43 stops there. While on route, the bus goes past what the speaker thought was the stop. S asks the driver:

a. (What're you doing?) Doesn't this bus stop at the Hampshire Mall?

$\rightsquigarrow \mathrm{S}$ had prior expectation that the bus stopped here $(p)$ and thinks driver may have skipped the stop, so is double-checking the prior expectation that $p$.

(Outer NPQ)

b. (Oh no!) Does this bus not stop at the Hampshire Mall?

$\rightsquigarrow \mathrm{S}$ had a prior expectation that the bus stops there $(p)$ and now thinks she may have been wrong, so is double-checking the implied inference that $\neg p$.

(Inner NPQ)

Our example employs a HiNPQ for the outer reading and a LowNPQ for the inner reading. The HiNPQ from Ladd's suggestion scenario (27) is also an OuterNPQ because it expresses the speaker's request for confirmation of her prior positive expectation that there is a vegetarian restaurant. One may legitimately wonder whether inner and outer negation readings correlate strictly to the (surface) placement of negation (HiNPQs/outer vs. LowNPQs/inner). The answer to this question, at least 
for the English data, is not so straightforward due to cross-speaker variation. Ladd reports that English HiNPQs can have both outer and inner readings (though this judgment of ambiguity doesn't hold across all English speakers, and some accept only the outer reading with high negation). ${ }^{18}$ The example below is Ladd's own variant to (27):

\section{Ladd's 1981 scenario v. 2 (S expected $p$, evidence for $\neg p$ )}

Bob is visiting Kathleen and Jeff in Chicago while attending CLS.

Bob:I'd like to take you guys out for dinner while I'm here - we'd have time to go somewhere around here before the evening session tonight, don't you think?

Kat: I guess, but there's not really a place to go in Hyde Park.

Bob:Oh really, isn't there a vegetarian restaurant around here?

Kat: No, about all we can get is hamburgers and souvlaki.

This example, according to Ladd, is an example of inner negation reading: Bob assumed the truth of the proposition that there is a vegetarian restaurant around here $(p)$, but he had to infer from Kathleen's response (contextual evidence) that this proposition might actually be false, and is using the HiNPQ to double check on the newly implied inference that $\neg p$ (inner negation reading) due to epistemic conflict.

Ladd then argues that, at least for English, the difference between inner and outer readings is a genuine syntactic/semantic ambiguity, involving a difference in the scope of negation and an operator whose nature remains to be determined. In the case of outer negation readings, Ladd takes a sentential negation to be outside the scope of the operator, which intervenes for licensing purposes - thus the proposition being double-checked has positive polarity. On the other hand, in the case of inner negation readings, sentential negation is below the operator, and the proposition being doublechecked has negative polarity. Ladd uses data from polarity items as a probe into a scope-based analysis; see Romero \& Han (2004) for much further discussion of this diagnostic. In particular, these authors show that a PPI disambiguates an NPQ in favor of the outer reading and that an NPI (choosing NPIs that do not already have questions as a licensing environment) disambiguates an NPQ in favor of the inner

18 Based on consultation with many native speakers, there is substantial variation across speakers in whether inner readings are available (by all diagnostics) with preposed negation. The situation is summarized below.

a. Group 1: HiNPQ: only outer readings LowNPQ: only inner readings

b. Group 2 (includes Ladd 1981, and the dialect analyzed by Romero and Han) HiNPQ: ambiguous between inner and outer readings LowNPQ: only inner readings 
Italian polar questions and 'mica'

reading (the $\%$ here indicates cross-speaker variation corresponding to the dialects described in fn. 18): ${ }^{19}$

A PPI disambiguates in favor of the outer reading

a. $\quad$ (after Ladd 1981 exx. 7-9, Han \& Romero 2004 ex. 6)

A: Ok, now that Stephen has come, we are all here. Let's go.

$\mathrm{S}: \quad$ Isn't $\mathbf{t}_{\text {Outer }}$ Jane coming too toPI $_{\text {? }}$ ?

( $\rightsquigarrow$ double-check prior expectation that Jane comes)

$\mathrm{S}^{\prime}:$ *Is Jane not $_{\text {Inner }}$ [ coming too $P$ PI $]$ ?

$\mathrm{S}^{\prime \prime}$ : \#Is Jane [ not $_{\text {Inner }}$ coming ] too tPPI $_{\text {? }}$ (blocked in this context)

b. (After Romero \& Han 2004 ex. 34)

A: Michael has not been happy with Sue since yesterday's meeting, and she's been ignoring the issue.

S: $\quad$ Shouldn't Outer $_{\text {She have talked to him already }}$ PPI?

$\mathrm{S}^{\prime}$ : *Should she not $_{\text {Inner }}$ [ have talked to him already $\mathbf{y P I}_{P P}$ ?

An NPI disambiguates in favor of the inner reading

a. A: Now that John said he is not coming, it's going to be just me and you. We should cancel the party.

$\mathrm{S}: \quad$ Is Jane not $_{\text {Inner }}$ coming either $_{N P I}$ ?

$(\rightsquigarrow$ double-check implied inference that Jane isn't coming)

$\mathrm{S}^{\prime}: \%$ Isn't $_{\text {Inner }}$ Jane coming either $_{N P I}$ ?

b. A: Michael has not been happy with Sue since yesterday's meeting, despite her attempt to apologize just now.

S: \% Shouldn't ${ }_{\text {Outer }}$ she have talked to him yet $_{N P I}$ ?

$\mathrm{S}^{\prime}$ : $\quad$ Should she not $_{\text {Inner }}$ [ have talked to him yet $_{N P I}$ ]?

Returning now to Italian, we have already seen that Italian NPQs, just like English NPQs, are only felicitous in contexts compatible with the speaker having a prior positive bias. We now show that Italian, despite surface appearances, has Ladd's inner vs. outer distinction. (See Höhle 1992, Büring \& Gunlogson 2000, Han \&

19 The additive particle too has classically been thought to be anti-licensed in negative contexts since Klima (1964), including in the polar questions literature, and for this reason we present it in the main text. However, Rullmann (2003) has argued that its distribution can be explained by a combination of its presupposition, a preference for low attachment, and competition with either, which Rullmann argues should be treated as an NPI. We have also provided examples with the uncontroversial PPI clause-final already as well; see Han \& Romero 2004 for further examples and Szabolcsi (2004), Giannakidou (2011) a.m.o for further discussion of PPI licensing. However, it is worth noting that on Rullmann's analysis, we might still expect the distribution of too to be diagnostic of the scope of negation, as originally assumed by Ladd. We leave it open as to whether some version of Rullmann's proposal might translate to the Italian PPI anche that we use below. 
Romero 2004 for arguments that a range of further languages including German, Spanish, Korean, and Bulgarian have a similar distinction.).

In Italian, we can construct a similar diagnostic using certain polarity items and their positive counterparts. We will employ the polarity items anche ('too/also') and neanche ('neither') to distinguish between the two readings. ${ }^{20}$ The data show that Italian NPQs can have both inner and outer readings, despite having only one surface position for negation. For instance, in the contradiction scenario in (46), $\mathrm{S}$ is double-checking the positive proposition $p$ "that A is (also) going" (outer negation reading). The motivation behind the double-checking move is an apparent epistemic conflict: contextual evidence contradicts $S$ 's prior expectation for $p$.

Drinks Context 1: S, A, and B are out for drinks. S and B want to go to a bar and start walking towards it. A appears to stay behind. S asks A:
S: (Che fai?)
Non ${ }_{\text {Outer }}$ vieni
anche $_{P P I}$ tu con noi?
(What do.2sg?) NEG come.2sg too you with us?
'(What are you doing?) Aren't you coming too?'

NPQs also license NPIs; moreover, when neanche ('neither') is used in an NPQ, it disambiguates in favor of the inner reading (double-checking implied contextual inference for $\neg p$ ). In (47) below, $\mathrm{S}$ is double-checking the implied proposition $\neg p$, i.e. "that A is not going"; as before the motivation behind the double-checking move is epistemic conflict: contextual evidence contradicts S's prior expectation for $p$.

Drinks context 2: S, A, B and C are out for drinks, and considering heading to a new bar. B tells them she is done for the night and leaves. S+C start walking toward the bar, and notice that $\mathrm{A}$ is also staying behind. $\mathrm{S}$ asks $\mathrm{A}$ :
S: (Oh no!) Non Inner vieni $_{\text {neanche }}$ NPI tu con noi?
NEG come.2sg neither you with us?
'(Oh no!) are you not coming either?'

Thus, the characterizing features of Italian NPQs can be summarized as follows:

Italian NPQs: 'Non vieni (anche ${ }_{P P I} /$ neanche $_{N P I}$ ) tu?'

\section{a. Speaker's prior bias: $p$}

20 We follow Giannakidou (2000), Chierchia (2006, 2013) in describing negative items in Italian as polarity items; see Franco et al. (2016) for discussion of anche as a PPI. The core contrast in declarative sentences when these items are in a post-verbal position is illustrated in (i-ii):

$$
\begin{aligned}
& \text { (*Non) Vengo } \text { anche }_{P P I} \text { io } \\
& \text { (*NEG) come.1sg too I } \\
& \text { 'I am (*not) coming too.' }
\end{aligned}
$$

(ii)

$$
\begin{aligned}
& * \text { (Non) vengo neanche } \text { nPI }_{N P} \text { io } \\
& \text { *(NEG) come.1sg neither I } \\
& \text { 'I am *(not) coming either' }
\end{aligned}
$$


Italian polar questions and 'mica'

b. Contextual evidence: $\neg p$ (or absent in suggestions)

c. Double-checking: $\mathrm{S}$ asks whether $\neg p$ to check on her prior bias for $p$ (OuterNPQ); or to check on the contextual evidence that $\neg p$ is in fact the case (InnerNPQ).

What about Mica-PQs? Despite mica's status as a negative element, Mica-PQs pattern with Outer-NPQs in licensing PPIs and anti-licensing NPIs. The question in (49) is ungrammatical with the NPI neanche, while the variant with the PPI anche is grammatical and would be felicitous in a scenario in which for e.g. the speaker told her younger sister to not go out with her and her friends, but is now faced with counter-evidence.

$$
\text { Che fai? Mica vieni }\{\text { anche } / * \text { neanche }\} \text { tu? }
$$

\section{Analyzing Biases}

In this section, we develop a novel account of biased PQs in Italian, and show how to extend it to Mica-PQs. We take as our starting point the Romero \& Han (2004), Romero (2014) account of biases in English PQs via common ground management operators, such as VERUM and FALSUM; however, we modify this account substantially to treat 'CG-management content' as presuppositional (providing contextual bias conditions), and to drastically simplify (and, we hope, clarify) the pragmatic reasoning that leads to evidential bias. We then develop an account of mica in this framework. We argue for a treatment of mica as a CG-management operator, FALSUM, but one that differs from the NPQ uses of that operator in terms of its perspectival anchoring. While VERUM and FALSUM mirror evidential operators in that they show interrogative flip, or what Garrett (2001) termed 'origo shift', mica remains stably anchored to the speaker. The analysis has the further advantage of providing a unified account of mica in PQs and declaratives, as well accounting for the scopal facts from 2.4 and the polarity licensing facts from the previous section.

\subsection{Common Ground Management}

Stalnaker (1978) famously proposed that in modeling assertions in a context, we need to think of that context as a common ground $(\mathrm{CG})$ : a set of propositions that discourse participants have publicly and mutually agreed to. This can be simplified to a context set, the intersection of propositions in the CG, which represents the shared information state of agents in a discourse. An assertion, on this view, proposes to add new information to the $\mathrm{CG}$, which results (if everything goes well) in a monotonic shrinking of the context set over the course of discourse. 
(50) Let a common ground $C G_{w}$ for some context be the set of propositions that discourse participants for that context have publicly accepted (abstracting away from time) in a world $w$.

The conversational move of assertion is the instruction or request to add the asserted proposition $p$ to the CG (see e.g. Roberts 1996, 2012) and it is governed by the maxim of Quality. One could accept a move, in which case the proposition asserted is added to the $\mathrm{CG}$.

Maxim of Quality: Try to make your contribution one that is true, specifically, (i) do not say what you believe to be false and (ii) do not say that for which you lack adequate evidence.

Following Farkas \& Bruce (2010) we assume that a default assertion (i) commits its author to the propositional content of the asserted sentence, (ii) raises an issue (the denotation of the sentence radical) and (iii) directs the conversation towards a unique resolution of that issue, namely confirmation of the assertion. Thus, an assertion yields an output context that is categorically biased in favor of confirmation of the asserted proposition. Default (= unbiased) Polar Questions, on the other hand, raise an issue and indicate two possible ways of updating the CG, corresponding to the two answers: "The context state after a default polar question is inquisitive with respect to the denotation of the sentence radical because the Projected State contains both future common grounds in which $p$ is added and future common grounds in which $\neg p$ is added" (Farkas \& Bruce 2010: 10).

While Stalnaker was primarily concerned with the role and result of conversational moves such as assertion, a substantial body of recent work suggests that natural languages contain rich sets of morphology for indicating meta-conversational information of various kinds (see e.g. Krifka 2008, Farkas \& Bruce 2010, Zimmermann 2011, Ginzburg 2012, Repp 2013, a.o.). Here we build most directly on Repp (2013), who refers to such items as common ground management operators.

An example of a meta-conversational move would be to challenge an interlocutor's assertion instead of accepting it. This sort of move is typically marked; for example, in English this could be done using a V-PPQ, as shown below.

S: I am going to Alex's party.

A: Are you really going? (I thought you hated Alex.)

In Repp's terms, therefore, it is plausible to take really to be a CG-management operator. CG-management operators indicate the status of a proposition relative to the CG and may play at least one of the following functions: (i) they indicate whether the proposition is part of the CG, or whether it is new; (ii) they indicate the interlocutor's current stance towards the proposition: whether the proposition is e.g. 
Italian polar questions and 'mica'

unexpected or obvious; and (iii) they indicate how the CG should develop: whether and with what degree of commitment on the side of the speaker, the proposition should become part of the CG or be removed from it. (Repp 2013:1). We adopt from Repp the following LF schema for the left periphery:

$$
\text { LF schema: [illocutionary-op [(CG-management-op) [proposition]]] }
$$

\subsection{VERUM and FALSUM}

On this view, Romero \& Han's VERUM operator is a special case of a CG-management operator, spelled out in English by epistemic really, (or, arguably, focal stress on polarity elements, i.e. comparable to Höhle's (1992) Verum focus; but see Gutzmann \& Miró 2011, Goodhue 2018a). This operator has the semantics of an epistemic modal, though it intuitively operates at a 'meta-level' with respect to discourse. The following is Romero \& Han's entry for VERUM (their ex. 43). In what follows, $x$ is a free variable whose value is contextually identified with the speaker in declaratives and the addressee in questions; $\operatorname{Epi}_{x}(w)$ the set of worlds conforming to $x$ 's knowledge in $w$; $\operatorname{Conv}_{x}\left(w^{\prime}\right)$ the set of worlds where all the conversational goals of $x$ in $w^{\prime}$ are fulfilled (e.g attain maximal information while preserving truth); $\mathbf{C G}_{w}$ is the Stalnakerian common ground at a world $w$, i.e. the set of propositions that the speakers assume to be true at $w$ (c.f. Stalnaker 1978).

$$
\begin{aligned}
& \llbracket \mathbf{V E R U M}_{i} \rrbracket^{g[x / i]}=\llbracket \text { really }_{i} \rrbracket^{g[x / i]}= \\
& \lambda p_{\langle s, t\rangle} \cdot \lambda w \cdot \forall w^{\prime} \in \operatorname{Epi}_{x}(w):\left(\forall w^{\prime \prime} \in \operatorname{Conv}_{x}\left(w^{\prime}\right):\left(p \in \mathbf{C G}_{w^{\prime \prime}}\right)\right)
\end{aligned}
$$

Paraphrase: $x$ is sure that, in all the worlds satisfying $x$ 's conversational goals, $p$ is added to the CG.

VERUM on this view is a perspectival operator: it introduces entailments about the state of the CG from the perspective of one of the participants in the discourse. The perspective taken by the operator is bound by the speech-act operator. That is, in assertions VERUM is speaker-oriented, and in questions, it is hearer-oriented. This behavior closely resembles the phenomenon of 'interrogative flip' in many languages with evidential systems (see Bhadra 2017 for a recent overview). As an example of the role of VERUM in assertions, consider (55). This scenario begins with $\mathrm{S}$ putting forward the unmarked assertion of the proposition that Tom is tired. A responds by arguing with this claim (a meta-conversational move itself), so the claim doesn't immediately become CG. S then responds with a meta-conversational reiteration: establishing over and above the initial claim their high degree of certainty in it, by indicating that they are certain that the proposition should be added to the CG. A then gives in and accepts the claim. 
Context: the hike

S: Tom is tired.

$\operatorname{AsSERT}_{S}$ [Tom is tired]

A: I am surprised, we have only walked for 10 minutes.

$\mathrm{S}$ : He really is tired. $\quad \operatorname{ASSERT}_{S}$ [VERUM $_{S}$ [Tom is tired]] ( $S$ is certain about adding [Tom is tired] to the $C G$ )

A: Ok, fine. $\quad(\Rightarrow$ 'Tom is tired' is added to CG.)

Repp additionally proposes that illocutionary negation corresponds to the metaconversational operator FALSUM, which is a VERUM with embedded negation:

$$
\begin{aligned}
& \llbracket \text { FALSUM }_{i} \rrbracket^{g[x / i]}= \\
& \lambda p_{\langle s, t\rangle} \cdot \lambda w . \forall w^{\prime} \in E_{p i}(w):\left(\forall w^{\prime \prime} \in \operatorname{Conv}_{x}\left(w^{\prime}\right):\left(p \notin C G_{w^{\prime \prime}}\right)\right)
\end{aligned}
$$

Paraphrase: $x$ is sure that, in all the worlds satisfying $x$ 's conversational goals, $p$ is not added to the CG.

FALSUM is in the general family of illocutionary or metalinguistic negative operators (see also Krifka 2017). An example can be found in denials. Depending on the context and on intonation, a negative sentence can be read in two ways: (i) as an assertion of a negative proposition, as in (57) or (ii) as a denial of a positive proposition, as in (58) - a common characteristic of illocutionary negation is that it carries stress (Horn 1985, van Leusen 2004). ${ }^{21}$

A: What do you think of Sam?

$\mathrm{S}$ : Sam is not smart. (negative assertion)

Denial Context

A: Sam seems smart.

S: Sam is NOT smart. [ASSERT [FALSUM $_{S}$ [Sam is smart]] ( $S$ is certain about not adding [Sam is smart] to the CG)

A major question at this stage is how, exactly, the CG-management content of a meta-conversational move relates to the prejacent. We will approach this by asking: what is at issue in a CG-managing move? There are two main answers. Romero \& Han (2004) as well as Repp (2013) and Frana \& Rawlins (2016) take the CGmanagement proposition itself to be at-issue. That is, S's response in (55) asserts that in all accessible worlds, the proposition that Tom is tired is added to the CG. The alternative possibility (Romero 2014) is that all that is at-issue in such a move is the prejacent of the CG-management operator; the CG-management content would then operate on another dimension, e.g. as a conventional implicature in the

21 For reasons of space, we will not consider the (very real) possibility that stressed negation in English should instead be analyzed in terms of the theory of focus; see Goodhue (2018a,b) for recent discussion. 
sense of Potts (2005) or as a presupposition (Yuan 2015). We briefly review two arguments for treating the CG-management content as not-at-issue, and then revise the current denotations of VERUM and FALSUM. The arguments point towards a multi-dimensional analysis of the differences between CG-managing operators and epistemic modal auxiliaries.

The first argument comes from a commonly used diagnostic for (non) atissueness in the evidential literature, the challengeability test, according to which only the at-issue content of a speaker's utterance can be accepted or rejected by an addressee (Faller 2002, Papafragou 2006, Murray 2017; but see Korotkova 2016a for a different account). With an epistemic modal, a denial can target the modal claim (in addition to the prejacent in some contexts), whereas in the case of VERUM/really, just like in the evidential case, the denial must target the embedded claim, not the meta-conversational claim about certainty:

A: The keys have to be in the car.

(Epistemic modal)

B: No, they don't have to be, they might be somewhere else.

A: Tom really is tired. (Epistemic conversational operator)

B: That can't be/You are wrong. $(=\neg[$ T. is tired $] / \neq \neg[$ A is sure that ...] $)$

(61) A: Real Madrid evidently not as good without Ronaldo.

B: That's not true/You are wrong.

(Evidential adverb; ex. via google)

( $=\neg[\mathrm{RM}$ is not as good without R.] $/ \neq \neg[$ It is evident to A that ...])

The second argument comes from the interaction of such operators with question meanings and answerhood licensing. As noted by Gutzmann \& Miró (2011), Romero (2014), a negative answer to a question containing an epistemic modal can be taken as negating the modalized epistemic proposition (thus, expressing lack of certainty). In contrast, the corresponding negative answer to a question containing epistemic really, or VERUM focus, can only mean that the negative alternative is true, and cannot express a lack of (un)certainty. This is expected if CG-managing operators, such as VERUM, are not part of the at-issue content.

(62) Epistemic modals
a. A: Are you sure/certain of going?
B: Yes (I am sure I am going) / No (I am not sure that I am going)
b. A: Could it rain later?
B: Yes, there's a 50\% chance.

(63) Epistemic conversational operator
A: Are you really going?
B: Yes (= I am sure I am going) 
B: No (I am not going; $\neq$ I am not sure I am going)

B: \#No, I am still unsure if I'm going.

Romero (2014) therefore revises the Romero \& Han entry for VERUM to move the modal formula out of the at-issue content (and adopts FALSUM with a similar tweak), but is non-specific about what kind of not-at-issue content it is (just terming it 'CG-Management-Content'). Gutzmann \& Miró (2011) give a rather different account of the content of VERUM (they deal only with declaratives, not PQs), but also move this content out of the at-issue content into the 'expressive' dimension. While we think that the basic move to not-at-issue content is necessary, the evidence for choosing between categories of not-at-issue meaning is somewhat more equivocal. Once again the situation resembles that of evidential marking, where the so-called 'family-of-sentences' tests (see e.g. Chierchia \& McConnell-Ginet 1990, Tonhauser et al. 2013, a.o.) are challenging to apply, because VERUM and FALSUM can't be embedded; embedded NPQs with whether seem to involve regular negation, e.g. do not indicate a speaker or attitude holder's prior beliefs or evidence. ${ }^{22}$ Though Gutzmann \& Miró (2011) take a stand in a particular direction, they also did not provide arguments for choosing expressive content over other options.

In what follows we will develop a new version of this proposal that treats CG-managing content as presuppositional, but we do not rule out the possibility of translating the analysis to other categories of not-at-issue meaning. The core intuition behind choosing a presuppositional account is that negation and mica in denials and PQs impose appropriateness conditions on input contexts, which lead to judgments of infelicity when these conditions fail. Since one of our primary desiderata is to capture these conditions, presuppositionality is a natural tool. To the extent that biased questions indicate new information (e.g. about the speaker's bias), we will derive it as an implicature, via Romero \& Han-style reasoning (to be developed in $\S 5.3$ ), but we suggest that the bias content that we encode lexically is not generally used to convey new information.

We will conclude this discussion by presenting an argument towards a presuppositional account of FALSUM in PQs, involving the interaction of HiNPQs and conditionals. One case where NPQs can embed with a biased meaning is in the consequent of a conditional question. Following Isaacs \& Rawlins (2008) we take it that the if-clause has to scope over a question operator, because it is providing a restriction to that operator, while FALSUM (on Repp's syntax at least, see (53)) must syntactically scope in the consequent below the if-clause. The question is if the not-at-issue implication of FALSUM, which for purposes of discussion we will assume is the CG-management content in (56), is interpreted locally or globally. On a

22 While really and similar adverbs can embed, they are typically assumed to be a different lexical item when embedded (see Romero \& Han 2004 fn. 11). 
Italian polar questions and 'mica'

presuppositional story we expect local interpretation to be possible in the consequent of conditionals (based on well-known filtering data; see Karttunen 1973 et seq). On e.g. a Pottsian conventional implicature analysis (Potts 2005), we would instead expect the implication to project globally. In (64) we see that the biased contribution of an NPQ in a conditional question gets conditionalized. That is, in $B^{\prime}$ in contrast to $B$, the speaker indicates a prior expectation that the party will be indoors if it rains. To make sense of this, the implication of FALSUM must be interpreted in the local context where the temporary assumption that it will rain is already in play, rather than escaping the conditional.

(64) A: It might rain later; you should bring a rain jacket.

B: Won't the party be indoors?

$\mathrm{B}^{\prime}$ : If it rains, won't the party be indoors? [If $r$ ], [Q [FALSUM p]]

\subsection{VERUM and FALSUM in Italian polar questions}

We give an account of the pragmatics of biased PQs that builds on Romero \& Han (2004)'s framework, keeping their syntax as well as the core of their pragmatic reasoning - that the use of a meta-conversational operator triggers reasoning about the choice of a complex discourse move over a simpler competitor. We depart from Romero \& Han (2004) in treating the contribution of CG-management operators as not at-issue (Gutzmann \& Miró 2011, Romero 2014). More specifically, we propose an analysis in which the meta-conversational content is modeled as a presupposition. As a result, our analysis avoids complex theoretical tools like biased partitions, (as in Romero \& Han 2004), and non-at-issue inquisitive content (as in Romero 2014). ${ }^{23}$

\subsubsection{The LFs of Polar Questions and an explanation of the polarity facts}

We adopt Romero \& Han (2004)'s LFs for PQs (with the innovation introduced by Romero (2014) of using FALSUM instead of $\neg$ VERUM), together with their account of inner/outer readings in correlation with polarity items (section 4.2) through an interplay of the CG-management operators VERUM/FALSUM and negation. In a nutshell, outer negation in NPQs does not introduce standard negation at LF. Instead, it corresponds to the negative operator FALSUM which, unlike logical negation, fails to license NPIs (or anti-license PPIs). Thus, it follows that NPIs are only licensed in

23 On Romero's 2014 proposal the partitioning effect of questions happens on the CG-management tier as well: for a biased PPQ the CG-management content consists of a biased partition where the choice is between absolute certainty about adding $p$ to the CG $\left(\operatorname{VERUM}_{H} p\right)$ and any other degree of certainty $\left(\neg\right.$ VERUM $_{H}$ p). However, Romero (2014) does not give an account of what is involved in having inquisitive non-at-issue content beyond a brief discussion in $\mathrm{fn}$. 8, nor does the paper provide a revision of the pragmatics in Romero \& Han (2004) that handles the new semantics. 
Inner-NPQs, where regular negation takes scope over the prejacent proposition and is below the (optional) VERUM operator.
a. V-PPQ: Are you really coming?/Are you COMING? [Q [VERUM [p]]
b. Outer-HiNPQ: Aren't you coming (too)?
[Q [FALSUM [p]]
c. Inner-HiNPQ: \%Aren't you coming (either)?
[Q [VERUM $[\neg[\mathrm{p}]]]$
d. Inner-LowNPQ: Are you not coming (either)? [Q [(VERUM) [ $\neg[\mathrm{p}]]$

We propose to extend this analysis to Italian PQs. As already noted, despite having only one surface position for negation, Italian NPQs also have inner and outer negation readings. We take this as evidence for postulating two types of negation; the outer one corresponding to the operator FALSUM, the inner one for regular negation. Thus, by the same logic, it follows that the PPI anche is licensed in Outer-NPQs because FALSUM, unlike regular negation, is not a PPI anti-licensor. Conversely, the NPI neanche is licensed in Inner-NPQs where we find standard negation.

$$
\begin{aligned}
& \text { a. V-PPQ: Veramente vieni? / VIENI? } \\
& \text { b. Outer-NPQ: Non vieni anche } \text { e }_{P I} \text { tu? } \\
& \text { c. Inner-NPQ: Non vieni neanche } \\
& N P I
\end{aligned}
$$

[Q [VERUM [p]]

[Q [FALSUM [p]]

[Q [(VERUM) [ $\neg[\mathrm{p}]]]$

\subsubsection{Meta-conversational content as presuppositional}

Our presuppositional entries for VERUM and FALSUM are presented in (67) and (68) respectively. The CG-management content of VERUM/FALSUM is rendered as a presupposition on the input context from the perspective of some individual in discourse. Adopting a term from the evidential literature, we will indicate the perspectival parameter of these operators with a contextual variable Origo $_{c}$. In root assertions, Origo ${ }_{c}$ is the speaker, and in root questions, Origo ${ }_{c}$ is shifted to the hearer. Following much of the literature on evidentials, we assume that the Origo parameter is effectively bound by the illocutionary operator in ForceP, without intending to presuppose that the ultimate analysis must literally involve binding. ${ }^{24}$

$$
\begin{aligned}
& \llbracket \text { VERUM } \rrbracket^{c, w}=\lambda p_{\langle s, t\rangle} \cdot p \\
& \text { Defined for } p, c, w \text { only if } \\
& \qquad \forall w^{\prime} \in \mathrm{Epi}_{\text {Origo }_{c}}(w):\left(\forall w^{\prime \prime} \in \operatorname{Conv}_{\text {Origo }_{c}}\left(w^{\prime}\right):\left(p \in \mathrm{CG}_{w^{\prime \prime}}\right)\right) \\
& \text { "Origo }{ }_{c} \text { is sure that, in all worlds satisfying their conv. goals, } p \text { is CG." }
\end{aligned}
$$

$\llbracket$ FALSUM $\rrbracket^{c, w}=\lambda p_{\langle s, t\rangle} \cdot \neg p$

Defined for $p, c, w$ only if

24 See Bhadra (2017) for a recent interface analysis of perspectival anchoring and a review of the possible analyses. 
Italian polar questions and 'mica'

$$
\forall w^{\prime} \in \operatorname{Epi}_{\operatorname{Origo}_{c}}(w):\left(\forall w^{\prime \prime} \in \operatorname{Conv}_{\text {Origo }_{c}}\left(w^{\prime}\right):\left(p \notin \mathrm{CG}_{w^{\prime \prime}}\right)\right)
$$

"Origo ${ }_{c}$ is sure that, in all worlds satisfying their conv. goals, $p$ is not CG."

As in Romero \& Han (2004), PQs with CG-management operators are metaconversational moves, which are subject to a discourse-economy constraint: ${ }^{25}$

Principle of Economy (after Romero \& Han 2004)

Do not use a meta-conversational move unless necessary (to resolve a Quality dilemma).

A 'quality dilemma' (our term) is when some agent $a$ in discourse is faced with one of these two possible situations:

\section{Quality Dilemmas}

a. Epistemic Conflict: $\mathrm{S}$ has a pre-existing bias (for $p$ or $\neg p$ ) and the context (e.g. the hearer) presents counter-evidence.

b. Lack of Evidence: $\mathrm{S}$ has a pre-existing bias for $p$, but not enough evidence to assert it and the context does not support either $p$ or $\neg p$.

The Principle of Economy is intended to explain why V-PPQs and HiNPQs are felicitous only in scenarios where the speaker held a prior expectation regarding the answer to their own question. In contradiction scenarios, where $\mathrm{S}$ believed $p$ and $\mathrm{H}$ produced evidence against $p, \mathrm{~S}$ is justified in questioning the appropriateness of adding $p$ (or the newly implied $\neg p$ ) to the CG in order to resolve the apparent epistemic conflict. In suggestion scenarios such as (27), where $\mathrm{S}$ believed $p$, but doesn't have enough evidence to assert it, she can use the meta-question move to double-check this belief and potentially gather evidence, while indicating the belief. It follows that in scenarios where the speaker holds no prior expectation regarding the answer to her PQ, V-PPQs and HiNPQs are predicted to be infelicitous, because they involve the use of a meta-conversational move without a justified reason, in violation of the Principle of Economy. A corollary of this is that when the metaconversational move is optional, as in some NPQs (e.g. LowNPQs in (41)), the Principle of Economy won't trigger and such questions are felicitous in neutral contexts.

Let us now turn to the derivation of the biases, starting with V-PPQs; recall that these PQs license the inference that the speaker had a prior expectation for

25 This principle doesn't apply to non-meta-conversational moves, e.g. plain assertions and simple PPQs. This is not to say that there is no competition effect of any sort between such moves, but if there is, its effect would not be the same. For example, if a speaker asks a PPQ ('Is $p$ the case?'), one cannot draw the conclusion that they lack evidence for $p$ : this empirically runs up against the evidence condition in (21). 
the negative answer to the question, and they are felicitous only in contradiction scenarios, where the context (e.g. the hearer) provides counter-evidence. We take the polarity of the speaker's prior bias for a V-PPQs to be derived as shown below. Because this is a question, Origo ${ }_{c}$ is resolved to the hearer, which we notate $h_{c}$.

$\mathrm{H}$ : I am going to the party.

ASSERT [p]

S: Are you GOING? / Are you really going? / Veramente vieni?

$$
\begin{aligned}
& \llbracket\left[\mathbf { Q } \left[\text { VERUM [p]]] } \rrbracket^{c, w}=\{\mathrm{p}, \neg \mathrm{p}\} \quad(\text { 'S asks } \mathrm{H} \text { whether } p \text { or not } p \text { ') }\right.\right. \\
& \text { Defined if } \forall w^{\prime} \in \mathrm{Epi}_{h_{c}}(w):\left(\forall w^{\prime \prime} \in \operatorname{Conv}_{h_{c}}\left(w^{\prime}\right):\left(p \in \mathrm{CG}_{w^{\prime \prime}}\right)\right) \\
& \text { " } h_{c} \text { is sure that in all the worlds satisfying } h_{c} \text { 's conv. goals } p \text { is CG" }
\end{aligned}
$$

The presupposition is met in the input context, given that $\mathrm{H}$ has just asserted $p$. By quality, if one asserts $p$, it follows that they believe $p$ to be true and that they have adequate evidence for $p$. Moreover, since the default outcome of an assertion is confirmation (Farkas \& Bruce 2010), it is reasonable to assume that, through their assertion, $\mathrm{H}$ conveys the expectation that $p$ will become CG. Note that since the presupposed content of VERUM in questions requires that $\mathrm{H}$ has indicated certainty for adding $p$ to the CG, suggestion scenarios (where contextual evidence is neutral) are automatically ruled out. S's epistemic bias can be derived via a competition effect, following the Principle of Economy: S chose a complex (meta-conversational) question ([Q [ VERUM [you go]]]) over a simpler competitor (same question without VERUM). She must have a reason to do so. Thus, by the Principle of Economy, $\mathrm{S}$ is facing a quality dilemma. Since lack of evidence is ruled out (as explained above), $\mathrm{S}$ must be facing epistemic conflict (contextual evidence contradicts their prior bias). Given that $\mathrm{H}$ gave evidence for $p$ ( $h_{c}$ goes), then $\mathrm{S}$ must have had a prior bias for $\neg p$, and is requesting confirmation for (double-checking) the newly implied proposition that $p$ because of epistemic conflict. ${ }^{26}$

Furthermore, the analysis explains why a V-PPQ is infelicitous in scenarios like our Good Manners v. 2 (34): the presupposition introduced by VERUM in '[Q [VERUM [you ate already]]]' would be satisfied in scenarios where $\mathrm{H}$ had indicated certainty about adding $p$ ( $=\mathrm{H}$ ate already) to the $\mathrm{CG}$. Such a requirement is not met in our scenario, where the evidence provided by $\mathrm{H}$ (barely not touching food) is not strong enough to imply their certainty for wanting to add $p$ to the CG. Summing up, the analysis derives the felicity conditions of V-PPQs of the form '[Q [VERUM $[\mathrm{X}]]]$ ', namely that they can be felicitously uttered in contradiction scenarios only, where contextual evidence - in the form of H's commitment towards $\llbracket X \rrbracket$ - contradicts the speaker's pre-existing bias for the negative answer to the question.

26 This logic is an evolution of Romero \& Han (2004), with the same basic shape, but with several of the more complicated components eliminated: we do not need recourse to biased partitions, and we do not need to reason about the choice of the pronounced alternative. 
Italian polar questions and 'mica'

Analogous reasoning can be applied to the derivation of the speaker's bias in Inner-NPQs, for instance, NPQs with low negation and the particle really:

H: I am not going to the party.

$\mathrm{S}$ : Are you really not going? / Veramente non vieni?

[ASSERT $[\neg p]]$

$\llbracket[\mathbf{Q}[$ VERUM $[\neg p]]] \rrbracket^{c, w}=\{\mathrm{p}, \neg \mathrm{p}\} \quad$ ('S asks H whether $p$ or not $p$ ') Defined if $\forall w^{\prime} \in \operatorname{Epi}_{h_{c}}(w):\left(\forall w^{\prime \prime} \in \operatorname{Conv}_{h_{c}}\left(w^{\prime}\right):\left(\neg p \in \mathrm{CG}_{w}^{\prime \prime}\right)\right)$

" $h_{c}$ is sure that in all the worlds satisfying $h_{c}$ 's conv. goals $\neg \mathrm{p}$ is CG"

The presupposition is met in this context since $H$ asserted $\neg$ p. As above, the speaker's epistemic bias can be derived via a competition effect, following the Principle of Economy: $S$ chose a complex (meta-conversational) question over a simpler competitor (same question without VERUM). She must have a reason to do so. Thus, by the Principle of Economy, $S$ is facing epistemic conflict (we know that "lack of evidence" is ruled out with VERUM). Given that $\mathrm{H}$ gave evidence for $\neg p$ ( $\mathrm{H}$ is not going), then $\mathrm{S}$ must have had a prior bias for $p$, and is requesting confirmation for (double-checking) the newly implied proposition that $\neg p$ because of epistemic conflict. ${ }^{27}$

Finally, Outer-NPQs contain FALSUM. These questions are felicitous both in contradiction scenarios and in suggestion scenarios. This follows from the fact that, unlike VERUM, FALSUM does not require the hearer to have expressed the intention of adding a given proposition ( $p$ or $\neg p$ ) to the CG. In fact, the non-at-issue content of FALSUM in questions is logically compatible with two possible states of affairs: (i) $\mathrm{H}$ is sure $\neg p$ should be CG; for e.g. $\mathrm{H}$ uttered/implied $\neg p$, or (ii) $\mathrm{H}$ has not taken a stance towards $p$ (e.g. $\mathrm{H}$ has professed discourse neutrality towards the $p / \neg p$ issue) and nobody else has taken a stance towards the issue (neutral evidence context). Case (i) corresponds to contradiction scenarios and case (ii) to suggestion scenarios. We illustrate with a contradiction scenario:

H: I am staying home.

$\mathrm{S}$ : Aren't you going out? / Non esci?

[ASSERT $[\mathrm{q}]] \Rightarrow \neg p$

【[Q [FALSUM [p]]] $\rrbracket^{c, w}=\{\mathrm{p}, \neg \mathrm{p}\} \quad$ ('S asks H whether $p$ or not $p$ ') Defined if $\forall w^{\prime} \in \operatorname{Epi}_{h_{c}}(w):\left(\forall w^{\prime \prime} \in \operatorname{Conv}_{h_{c}}\left(w^{\prime}\right):\left(p \notin \mathrm{CG}_{w}^{\prime \prime}\right)\right)$

" $h_{c}$ is sure that in all the $w$ satisfying $h_{c}$ 's conv. goals, $p$ is not CG."

The presupposition is met in this context since $\mathrm{H}$ asserted $q$, which implies $\neg p$. As before, S's epistemic bias is derived via a competition effect: $\mathrm{S}$ chose a complex (meta-conversational) question over a simpler competitor (same question without

27 Remember that Low-NPQs do not have to involve a VERUM operator; in cases where VERUM is absent, these questions would work just like regular 'neutral' PQs with propositional negation. 
FAlsum). She must have a reason to do so. Thus, by the Principle of Economy, she is facing a quality dilemma. Given that $\mathrm{H}$ gave evidence for $\neg p$, then $\mathrm{S}$ must have had a prior bias for $p$. Another possibility, compatible with $\mathrm{H}$ being certain about $p$ not being CG, would be that $\mathrm{H}$ did not take a stance with respect to $p$, as in suggestion scenarios. In both cases, the speaker wants to double-check their prior bias that $p$ (outer negation reading) because of epistemic conflict (contradiction scenarios), or lack of evidence (suggestion scenarios).

Summing up, the analysis derives the felicity conditions of biased questions (V-PPQs, Outer and Inner NPQs), namely that they can be felicitously uttered in contradiction scenarios, where contextual evidence contradicts the speaker's prior bias for the answer to the question. Furthermore, it follows that only Outer-NPQs are felicitous in suggestion scenarios. This is because FALSUM stays for lack of certainty for adding $p$ to the $\mathrm{CG}$, which is compatible with evidence against $p$ (contradiction scenarios) but also lack of compelling evidence (suggestion scenarios). The analysis also derives parallel licensing facts to English, despite surface differences.

\section{Mica and bias reversal}

The CG-managing operators VERUM and FALSUM are perspectival operators: they introduce information about the state of the CG explicitly anchored to the perspective of one of the discourse participants. The perspective taken by the operator is effectively 'bound' by the speech-act operator (Romero \& Han 2004). That is, in assertions VERUM/FALSUM are speaker-oriented, and in questions, they are hearer-oriented. As we have noted, this situation resembles the common behavior of interrogative flip seen with evidential marking cross-linguistically (Garrett 2001, Speas \& Tenny 2003, Murray 2017, Korotkova 2016b, Bhadra 2017 among others).

Our proposal for mica is that it is the same kind of perspectival operator, but without the flip: mica introduces a FALSUM operator that, rather than having bound perspective variables, has its perspective necessarily anchored to the speaker. This makes mica analogous to the type of evidential recently discussed by Bhadra (2017) (focusing on Bangla) that does not undergo interrogative flip. We will show that this perspectival stability inverts the pragmatic reasoning triggered by the use of a CG-management operator in regular NPQs, leading to a reversal in the polarity of the bias on the part of the participants in discourse. Under our proposal, the bias reversal phenomenon for mica amounts to lack of interrogative flip.

We earlier presented arguments that FALSUM should be treated as not-at-issue and one argument for a specifically presuppositional account; the arguments for not-at-issueness were straightforward and apply directly to mica as well, though the arguments for presuppositionality were somewhat equivocal. The situation for deciding among types of not-at-issue content is not much easier for mica: once again, 
the family-of-sentences largely do not apply, since mica is hard to embed; it can't occur in the antecedent of conditionals, with a higher negation ("It is not the case that (non)...mica $p^{\prime \prime}$ ), or in alternative questions. However, we do have one interesting case: mica can embed under certain attitude verbs. In (77) the projective content is the implication that Carla - not the speaker - is certain that $p$ should not be CG ( $p=$ Gianni stole the printer); thus the contrast between the two possible continuations (importantly, the global assertion with just plain negation non would be acceptable). In these cases we see what Tonhauser et al. (2013) described as 'obligatory local effect' - the anchor/origo for mica must be the attitude holder, not the speaker, and the implication acts as if it is embedded in the belief context. This data is suggestive of a presuppositional analysis, in that the other English triggers showing obligatory local effect for Tonhauser et al. (2013) are traditional presupposition triggers. ${ }^{28}$

Context: A printer in the office got stolen, and Gianni is the rumored thief.

Carla dice che non è stato mica Gianni a rubare la stampante, \#ma Carla says that NEG is been MICA Gianni to steal the printer, \#but non ne è certa/ma io ne sono certa.

NEG of-it be.3SG certain/but I of-it be.1SG certain.

'Carla says that it wasn't Gianni who stole the printer, \#but she is not certain about it/but I am certain about it.'

Our entry for mica is given in (78). For the moment, we will take it to be a lexical property that mica is speaker-oriented (Origo ${ }_{c}$ is resolved to the speaker, which we notate $s_{c}$ ), though we return to this below. ${ }^{29}$

$$
\begin{aligned}
& \llbracket \text { mica } \rrbracket c, w=\lambda p . \neg p \\
& \text { Defined for } p, c, w \text { only if } \\
& \qquad \forall w^{\prime} \in \operatorname{Epi}_{s_{c}}(w):\left(\forall w^{\prime \prime} \in \operatorname{Conv}_{s_{c}}\left(w^{\prime}\right):\left(p \notin C G_{w^{\prime \prime}}\right)\right)
\end{aligned}
$$

Definition is equivalent to: $\llbracket$ mica $\rrbracket^{c, w}=\llbracket \mathbf{F A L S U M} \rrbracket^{c / \text { Origo } \rightarrow s_{c}, w}$

28 We leave open the question of what the exact mechanism is for the local effect in this case. One possibility is that projection is blocked because 'Origo' is bound locally by a doxastic operator. If mica were maximally projective (e.g. Potts-style CI-content), but required local binding of the origo variable, we might expect overall infelicity when embedded under attitude verbs, contrary to fact. One may also wonder whether mica exhibit 'strong contextual felicity' effects, another test used by Tonhauser et al. (2013) to diagnose presuppositional content. However, as we have shown, although mica gives rise to contextual felicity effects - in that it is infelicitous in a neutral context, like e.g.(35), it can also be used discourse-initially (as in polite requests or in the paranoid scenario), as long as the inference can be easily accommodated.

29 Where $x$ is a named slot in $c$, the notation $c / x \rightarrow y$ indicates a modified context where $x$ is evaluated as $y$ relative to that context. 
In assertions, perspectival stability has no effect: Origo $_{c}$ in regular FALSUM would be bound to the speaker regardless. For questions, the prediction is that mica in PQs does not undergo interrogative flip, remaining anchored to the speaker, even though regular FALSUM would have a flipped Origo ${ }_{c}$.

$\llbracket[\mathbf{Q}[$ mica $[\mathbf{p}]]]]^{c, w}=\{\mathrm{p}, \neg \mathrm{p}\} \quad$ ('S asks H whether $p$ or not $p$ ') Defined if $\forall w^{\prime} \in \operatorname{Epi}_{s_{c}}(w):\left(\forall w^{\prime \prime} \in \operatorname{Conv}_{s_{c}}\left(w^{\prime}\right):\left(p \notin \mathrm{CG}_{w^{\prime \prime}}\right)\right)$ " $s_{c}$ is sure that in all the $w$ satisfying their conversational goals $p$ is not CG"

Just as in the case of hearer oriented FALSUM, this presupposition can be met in two ways: (i) in the input context, $\mathrm{S}$ is sure that $p$ is not $\mathrm{CG}$ because she believes $\neg p$ to be $\mathrm{CG}$, or (ii) $\mathrm{S}$ is sure that $p$ is not (yet) $\mathrm{CG}$ because nobody has taken a stance towards $p$ (or $\neg p$ ) - the context is neutral with respect to the issue. To see this in example form, let us revisit the contradiction scenarios used before:

Context: good manners v. 1 (S expected $p$, evidence against $p$ )

Clara invites Miles for drinks and tells him to come after dinner. When he gets there, Miles asks if she has any food. Clara asks him:
a. Non hai già mangiato?
b. \#Mica hai già mangiato?

(81) Context: good manners v. 2 (S expected $\neg p$, evidence for $p$ )

Clara invites Miles for dinner and makes clear to him that she will prepare her best dishes. At dinner Miles barely touches any food. Clara asks him:
a. \#Non hai già mangiato?
b. Mica hai già mangiato?

The presupposition introduced by mica is met in the second scenario only, where the speaker - prior to her own question - believed $\neg p$ (= Miles has not eaten already) to be CG. The mica-PQ presupposes certainty that $p$ ( $H$ ate already) should not be common ground; this presupposition is satisfied in Good manners v. 2 because $S$ believed this was an established expectation, so $\neg p$ ought to have been common ground in the input context. However, this is a question and so the speaker isn't sure, relative to the current context. Moreover, it is a meta-question, so the speaker is trying to resolve some epistemic or evidential conflict in the current context. In this case, there is contextual evidence against their prior expectation, in the form of Miles' apparent lack of hunger, and so they do not have sufficient evidence to decide the question themselves. However, Miles should certainly be able to report on his own hunger, and so would be in possession of appropriate evidence to decide whether adding $p$ to the CG is compatible with quality from the speaker's (or any) perspective. Consequently, the mica-PQ is felicitous in this context for indicating the speaker's prior expectation that Miles would not eat. 
Italian polar questions and 'mica'

The opposite holds for the Outer-NPQ that is felicitous in good manners v. 1 only. The presupposition of hearer-oriented FALSUM is straightforwardly met in this context since H (Miles) implies - through his request for food - that he didn't eat already, indicating that $\neg p$ should be common ground, from his perspective. As in the previous cases, the speaker's epistemic bias can be derived via a competition effect. By the Principle of Economy, the speaker is facing a quality dilemma. Given that $\mathrm{H}$ gave evidence for $\neg p$, then $\mathrm{S}$ must have had a prior bias for $p$.

Furthermore, the analysis makes the welcome prediction that mica-PQs and V-PPQs won't have the same felicity conditions: recall from section 3.3 that, unlike a mica-PQ, a V-PPQ is not acceptable in the Good Manners v. 2 scenario. In fact, despite sharing the same type of prior speaker bias, the content of the presupposition introduced by the two CG-management operators in PQs is not the same: while VERUM presupposes the hearer's certainty for $p$ being CG, which is too strong to be satisfied in our scenario (where Miles's indication is very indirect), mica requires the speaker's certainty for $p$ not being CG, which is instead satisfied in the scenario.

Finally, this analysis predicts the polarity licensing data for mica. Recall that mica in PQs does not license NPIs and does not anti-license PPIs (49). Given that mica introduces FALSUM and we have already established that FALSUM, unlike logical negation, does not license NPIs (or anti-license PPIs), we predict that mica-PQs will behave exactly like Outer-NPQs with respect to licensing of polarity items.

Before proceeding to assertions, we will briefly sketch three hypotheses about why it is that mica is perspectivally stable. The first is that, in line with our presentation so far, as well as Frana \& Rawlins (2016), the reference to the speaker is just a lexical property of mica. We know of nothing that would rule out this possibility, but will consider two hypotheses from which speaker anchoring might follow. These build on recent work by Bhadra (2017) on variation in interrogative flip for evidentials across languages. Bhadra's core proposal is that interrogative flip happens when an evidential's perspectival anchor is determined by a speech-act operator. Thus, following Bhadra (2017) on Bangla, the second hypothesis is that mica occurs in the analogue of rising declaratives, not 'true' questions. In Bangla, Bhadra argues that there are no true PQs, which generally leads to a lack of interrogative flip in the language. However, in Italian we see interrogative flip in PQs with veramente and plain negation, so the hypothesis must be more limited relative to Bangla - at least some PQ-like utterances would need to involve genuine PQs. ${ }^{30}$ The third hypothesis, also in line with (but not directly predicted by) Bhadra (2017), is that mica scopes high enough that it can never have its perspectival anchor shifted to the hearer, i.e. it

30 The intonational evidence we have examined in Italian is fairly inconclusive about differentiating 'true' PQs from something more declarative, where the word order is the same. That there is such a distinction is actually an intuition some speakers have, but one that requires more investigation than we can do here. 
actually scopes above the question operator; we would also need to assume that the unmarked Origo is the speaker. ${ }^{31}$ We have already provided a lower bound for mica at LF that is high in the left periphery, so this third hypothesis would be a natural extension of the scopal evidence examined earlier.

In summary, our proposal is that a question of the form "mica $p$ ?" presupposes that the speaker is certain about $p$ not being $C G$, leading to the expression of a mismatch in expectation with the current context. This presupposition can be met in two ways. Either S's certainty follows from a prior bias for $\neg p$, in which case the reason for still posing the question would be epistemic conflict, i.e., that $\mathrm{H}$ implied $p$ to be true, or some other type of contextual evidence against $\neg p$ (contradiction scenarios). The other possibility, compatible with $\mathrm{S}$ being certain about $p$ not being (yet) CG, would be that no one has yet taken an explicit stance towards the $p / \neg p$ issue. One reason for posing the question could be to double-check on their prior bias that $\neg p$ is still the case, as in the paranoid scenario in (36). Another reason, as in the polite requests, $\mathrm{S}$ thinks that $p$ is possible — but for politeness they want to be explicit about the fact that there is no (public) reason to expect $p$, giving $\mathrm{H}$ an easy path towards saying denying their request.

\subsection{Back to 'mica' in assertions}

Our proposal for mica in declaratives is that, just as in PQs, it expresses a form of meta-conversational negation, which we have treated as a subjective FALSUM operator. Since assertions are speaker-oriented already, the special perspectival properties of mica (vs. regular FALSUM) neutralize, and the operator remains speaker-oriented. This effectively turns previous accounts on their head, aside from Squartini (2017): Cinque (1976) (see also Zanuttini 1997, Penello \& Pescarini 2008, Pescarini 2009) suggests that mica is a presupposition trigger, a sentence of the form (non) mica $p$ asserts that $\neg p$ and presupposes that $p$ was expected. On our proposal, the inference that $p$ was expected is derived via a competition effect, whereas the presupposition (just as in PQs) is that the prejacent $p$ is not taken to be CG, from the speaker's perspective. We therefore capture the insight of the previous accounts of mica in assertions, while providing a proposal that can account for the wider range of data and unify the use of mica in assertions and PQs. Our proposed LF for a mica assertion as in (82) is illustrated in (83); this denotation is the same as $\llbracket\left[\right.$ ASSERT [FALSUM [p]]] $\rrbracket^{c, w}$ would be.

H: Luca è sposato. ('Luca is married').

[ASSERT [p]]

$\mathrm{S}$ : Luca non è mica sposato.

[ASSERT [MICA [p]]]

31 This would also commit us compositionally to certain kinds of question operators that do not encode a negative alternative in the semantics, e.g. that proposed by Biezma \& Rawlins (2012, 2017). 
Italian polar questions and 'mica'

$\llbracket[\operatorname{ASSERT}[\operatorname{MICA}[\mathbf{p}]]] \rrbracket^{c, w}=\lambda w . \neg p(w)$

Defined only if $\forall w^{\prime} \in \operatorname{Epi}_{s_{c}}(w):\left(\forall w^{\prime \prime} \in \operatorname{Conv}_{s_{c}}\left(w^{\prime}\right):\left(p \notin \mathrm{CG}_{w^{\prime \prime}}\right)\right)$

" $s_{c}$ is sure that in all the $w$ conforming to their conv. goals, $\mathrm{p}$ is not CG."

Remember that the presupposition of FALSUM can, in principle, be satisfied in two ways: (i) in the input context, $\mathrm{S}$ is sure that $p$ is not $\mathrm{CG}$ because $\mathrm{S}$ believes $\neg p$ to be $\mathrm{CG}$, or (ii) $\mathrm{S}$ is sure that $p$ is not (yet) CG because nobody has taken a stance towards $p$ (or $\neg p$ ) - the context is neutral with respect to the issue. In the case of assertions, the at-issue content filters out case (ii), since $\mathrm{S}$ explicitly takes a stance towards the $p$ or $\neg p$ issue by asserting $\neg p$. The pragmatic reasoning follows the usual steps. $\mathrm{S}$ chose a meta-conversational move over a simpler competitor (a negative assertion without MICA), thus by Economy, S must be facing a Quality dilemma. Since case (ii) is filtered out, $\mathrm{S}$ must be facing epistemic conflict, thus $p$ was assumed/expected (condition satisfied in the dialogue above because $\mathrm{H}$ asserted $p$ ). Crucially, we take it that the prior assertion by $\mathrm{H}$ must be treated as a 'proposal' in the sense of Farkas \& Bruce (2010), and thus not yet CG at the time of the response: $\mathrm{S}$ is indicating by presupposition that $p$ should not be CG, and even perhaps indicating that H's assertion (from S's perspective) wasn't warranted.

This proposal straightforwardly captures the facts we have introduced about mica in assertions. First, its licensing conditions - mica requires a salient expectation to deny. As with PQs, a FALSUM-based assertion is meta-conversational, and leads to reasoning involving the Principle of Economy. Because the speaker chose a metaconversational move of type (i), they must be assumed to have some evidence that rules out $p$, and must be assumed to have some reason to provide evidence ruling out $p$ - there must be something to have the conflict with. Consequently, a mica assertion will imply that the context provides some salient claim or expectation that $p$ for the mica assertion to strongly deny; the denied proposition need not have a linguistic antecedent as long as it is inferrable. If there is no such salient expectation, then the utterance will be a violation of the Principle of Economy.

While this account does not involve a presupposition that $p$ is expected, it derives a very similar inference given the semantics of FALSUM, at the same time explaining the intuition that mica assertions are used as denials. The account thus preserves Cinque's intuition, but derives it in a very different form. In fact, our proposal does better than Cinque's original presuppositional account in that it captures certain otherwise mysterious contrasts. Imagine a context in which an IKEA delivery person poses the questions below to a customer. In both examples, a PQ is used to inquire whether a certain proposition is true or false. The difference is that, buildings stereotypically have elevators, but not escalators; yet the use of mica in the customer's response is perfectly felicitous in (84b), but sounds very rude in (84a). The contrast does not follow from Cinque's analysis, in fact the opposite should hold given that 
the prejacent of mica is a stereotypical expectation in (84a), but not in (84b). If stereotypical expectations are not a factor, then the analysis would still wrongly predict that there should be no contrast between the two examples.

a. A: Does your building have an elevator?

B: No, il mio palazzo non ha (\#mica) un ascensore. "No, my building does not have (\#MICA) an elevator."

b. A: Does your building have an escalator?

B: No, il mio palazzo non ha (mica) una scalamobile. "No, my building does not have (MICA) an escalator."

Instead, the contrast above follows neatly from our analysis. Only in (84b), $\mathrm{S}$ is justified in taking for granted that it is not CG that S's building has an escalator. The opposite holds for (84a); here $S$ would not be justified in assuming that the proposition that their building has an elevator should not be in the $\mathrm{CG}$, given that it would be a very common thing to assume.

Finally, the account of the scopal facts in section 2.3 follows from the nature of CG-managing operators, which scope high on the left periphery, like discourse particles (Zimmermann 2011); something that wouldn't be explained if mica were a regular negation that is presuppositional. ${ }^{32}$

\section{Conclusions}

In this paper we have developed a new account of Italian polar questions as introducing presuppositional meta-conversational operators that are perspectival. Based on the presuppositional treatment of these operators, we have presented a new, and we hope, cleaner, version of the logic by which the biased 'epistemic inferences' of Romero \& Han (2004) can be inferred from both questions and declaratives with meta-conversational content. The star of the paper is the particle mica, which shows up in both assertions and polar questions, with a complex distribution and interaction with negation. Building on work on evidential operators, we proposed that meta-conversational operators undergo interrogative flip (something already implied by Romero \& Han 2004, but not under that name; our contribution here is

32 The analysis would also explain why mica leads to binding blocking effects. As shown below when mica intervenes between a quantifier and a bound variable, the sentence is marked. Related to that is the fact that mica is banned from restrictive relative clauses, as well as from constituent questions Cinque (1976). Following Kratzer (1999) and Zimmermann (2008) on discourse particles, we suggest that these three effects can be given a unified account under the assumption that mica selects a closed proposition (i.e., a proposition with no variables bound from above).

(i) Ogni candidato che ha partecipato al concorso non lo ha (*mica) superato.

'Every candidate $x_{i}: x_{i}$ took the exam, NEG $x_{i}\left({ }^{*} \mathrm{MICA}\right)$ passed it.' 
to link this idea to the larger literature on interrogative flip), but that mica does not undergo interrogative flip - it is inherently speaker-oriented. Italian, though lacking a grammatical evidential system, therefore is an example of a language that mixes both standard interrogative flip behavior (Garrett 2001, etc.) with non-flip behavior that has been less commonly described (Bhadra 2017). This account of mica as a perspectivally stable metaconversational FALSUM operator fully explains the complex distribution of the particle, as well as many related observations, including scopal facts and polarity licensing.

This project ties into the larger open question of why interrogative-flip-like or 'origo shift' effects can happen or not happen; previous work has approached this on a language-by-language basis (Bhadra 2017) or simply taken it to always occur (Korotkova 2016b). Italian contributes to this question by suggesting that a more

fine-grained parameter is necessary, i.e. a mechanism for variation between particular constructions or items. We have suggested two possibilities that could account for the data in Italian: variation among question-like clause types (following Bhadra 2017) or variation in the scope of particles (following, roughly, syntactic work on the left periphery).

We end with a prediction: there might be many languages that show mixed flip behavior, when the right semantics-pragmatics interface elements (e.g. particles) are examined, and the scope of interrogative flip extends beyond strict definitions of evidentials - and understanding the conditions for anchoring behavior at a finegrained level is crucial to an account of force at the semantics-pragmatics interface.

\section{References}

AnderBois, Scott. 2011. Issues and alternatives: UC Santa Cruz Ph.D. dissertation. Asher, Nicholas \& Brian Reese. 2005. Negative bias in polar questions. In Emar Maier, Corien Bary \& Janneke Huitink (eds.), Proceedings of Sinn und Bedeutung 9, 30-43.

Bhadra, Diti. 2017. Evidentiality and questions: Bangla at the interfaces: Rutgers $\mathrm{PhD}$ dissertation.

Biezma, Maria \& Kyle Rawlins. 2012. Responding to alternative and polar questions. Linguistics and Philosophy 35. 261-406. https://doi.org/10.1007/s10988-0129123-z.

Biezma, María \& Kyle Rawlins. 2017. Or what? Semantics \& Pragmatics 10 (early access). http://dx.doi.org/10.3765/sp.10.16.

Bolinger, Dwight. 1978. Yes-no questions are not alternative questions. In Henry Hiz (ed.), Questions, 87-105. D. Reidel Publishing Company.

Borkin, Ann. 1971. Polarity items in questions. In CLS 7, 53-63. 
Büring, Daniel \& Christine Gunlogson. 2000. Aren't positive and negative polar questions the same? Manuscript, UCSC/UCLA. https://semanticsarchive.net/ Archive/mYwOGNhO/polar_questions.pdf.

Chierchia, Gennaro. 2006. Broaden your views: Implicatures of domain widening and the "logicality" of language. Linguistic Inquiry 37. 535-590. https://doi. org/10.1162/ling.2006.37.4.535.

Chierchia, Gennaro. 2013. Logic in grammar: Polarity, free choice, and intervention. Oxford University Press. http://doi.org/10.1093/acprof:oso/9780199697977.001. 0001.

Chierchia, Gennaro \& Sally McConnell-Ginet. 1990. Meaning and grammar. MIT Press.

Cinque, Guglielmo. 1976. 'mica'. Annali della Facoltà di Lettere e Filosofia dell'Università di Padova 1. 101-112.

DeLancey, Scott. 1997. Mirativity: the grammatical marking of unexpected information. Linguistic Typology 1. 33-52. https://doi.org/10.1515/lity.1997.1.1.33.

D'Imperio, Mariapaola. 2002. Italian intonation: an overview and some questions. Probus 14. 37-69. https://doi.org/10.1515/prbs.2002.005.

Domaneschi, Filippo, Maribel Romero \& Bettina Braun. 2017. Bias in polar questions: evidence from English and German production experiments. Glossa 2. 1-28. http://doi.org/10.5334/gjgl.27.

Faller, Martina. 2002. Semantics and pragmatics of evidentials in Cuzco Quechua: Stanford University Ph.D. dissertation.

Farkas, Donka \& Kim Bruce. 2010. On reacting to assertions and polar questions. Journal of Semantics 27. 81-118. https://doi.org/10.1093/jos/ffp010.

Farkas, Donka \& Floris Roelofsen. 2017. Division of labor in the interpretation of declaratives and interrogatives. Journal of Semantics 1-53. https://doi.org/10. 1093/jos/ffw012.

Frana, Ilaria \& Kyle Rawlins. 2016. Italian 'mica' in assertions and questions. In Nadine Bade, Polina Berezovskaya \& Anthea Schöller (eds.), Proceedings of Sinn und Bedeutung 20, 234-251.

Franco, Irene, Olga Kellert, Guido Mensching \& Cecilia Poletto. 2016. A diachronic study of the (negative) additive anche in Italian. Caplletra 61. 227-258.

Garrett, Edward J. 2001. Evidentiality and assertion in Tibetan: UCLA Ph.D. dissertation.

Garzonio, Jacopo \& Cecilia Poletto. 2009. Quantifiers as negative markers in Italian dialects. Linguistic Variation Yearbook 9. 127-152. https://doi.org/10.1075/livy. 9.04gar.

Giannakidou, Anastasia. 2000. Negative... concord? Natural Language and Linguistic Theory 18. 457-523. https://doi.org/10.1023/A:1006477315705. 
Italian polar questions and 'mica'

Giannakidou, Anastasia. 2011. Negative and positive polarity items. In Claudia Maienborn, Klaus von Heusinger \& Paul Portner (eds.), Semantics: An international handbook of natural language meaning, vol. 2, 1660-1712. Mouton de Gruyter.

Ginzburg, Jonathan. 2012. The interactive stance: meaning for conversation. Oxford University Press. https://doi.org/doi.org/10.1093/acprof:oso/9780199697922. 001.0001.

Goodhue, Daniel. 2018a. A minimal theory of verum focus and context dependent bias in questions. In Sherry Hucklebridge \& Max Nelson (eds.), Proceedings of NELS 48, .

Goodhue, Daniel. 2018b. On asking and answering biased polar questions: McGill University Ph.D. dissertation.

Grice, Martine, Mariapaola D’Imperio, Michelina Savino \& Cinzia Avesani. 2005. Strategies for intonation labelling across varieties of Italian. In Sun-Ah Jun (ed.), Prosodic typology: The phonology of intonation and phrasing, 362-389. Oxford University Press.

Groenendijk, Jeroen \& Martin Stokhof. 1984. Studies in the semantics of questions and the pragmatics of answers: University of Amsterdam Ph.D. dissertation.

Gunlogson, Christine. 2001. True to form: Rising and falling declaratives as questions in english: UC Santa Cruz Ph.D. dissertation.

Gutzmann, Daniel \& Elena Castroviejo Miró. 2011. The dimensions of verum. In Olivier Bonami \& Patricia Cabredo Hofherr (eds.), Empirical issues in syntax and semantics 8, 143-165. CSSP.

Haegeman, Liliane. 2003. Conditional clauses: External and internal syntax. Mind \& Language 18. 317-339. https://doi.org/10.1111/1468-0017.00230.

Hamblin, C. L. 1973. Questions in Montague English. Foundations of Language 10. 41-53.

Han, Chung-hye \& Maribel Romero. 2004. The syntax of whether/Q...or questions: ellipsis combined with movement. Natural Language and Linguistic Theory 22. 527-564.

Heim, Irene. 1982. The semantics of definite and indefinite noun phrases: University of Massachusetts, Amherst PhD dissertation.

Höhle, Tilman N. 1992. Über Verum-Fokus im Deutschen. In Joachim Jacobs (ed.), Informationsstruktur und Grammatik, 112-141. Westdeutscher Verlag.

Horn, Laurence R. 1985. Metalinguistic negation and pragmatic ambiguity. Language 61(1). 121-174. https://www.doi.org/10.2307/413423.

Iatridou, Sabine. 1991. Topics in conditionals: MIT Ph.D. dissertation.

Isaacs, James \& Kyle Rawlins. 2008. Conditional questions. Journal of Semantics 25. 269-319. https://doi.org/10.1093/jos/ffn003. 
Karttunen, Lauri. 1973. Presuppositions of compound sentences. Linguistic Inquiry 4. 167-193.

Karttunen, Lauri. 1977. Syntax and semantics of questions. Linguistics and Philosophy 1. 3-44. https://doi.org/10.1007/978-94-009-9509-3_6.

Klima, E. 1964. Negation in English. In J. Katz \& J. Fodor (eds.), The structure of language, Prentice Hall.

Korotkova, Natalia. 2016a. Disagreement with evidentials: a call for subjectivity. In Julie Hunter, Mandy Simons \& Matthew Stone (eds.), Jersem: The 20th workshop on the semantics and pragmatics of dialogue, 65-75.

Korotkova, Natalia. 2016b. Heterogeneity and uniformity in the evidential domain: UCLA Ph.D. dissertation.

Kratzer, Angelika. 1986. Conditionals. In Anne M. Farley, Peter Farley \& Karl-Eric McCollough (eds.), Proceedings of CLS 22, 115-135.

Kratzer, Angelika. 1999. Beyond ouch and oops: How descriptive and expressive meaning interact. a comment on David Kaplan's paper. Cornell Conference on Theories of Context Dependency.

Krifka, Manfred. 2008. Basic notions of information structure. Acta Linguistica Hungarica 55. 243-276. https://doi.org/10.1556/ALing.55.2008.3-4.2.

Krifka, Manfred. 2017. Negated polarity questions as denegations of assertions. In Chungmin Lee, Ferenc Kiefer \& Manfred Krifka (eds.), Contrastiveness and scalar implicatures, Springer. https://doi.org/10.1007/978-3-319-10106-4_18.

Ladd, Robert. 1981. A first look at the semantics and pragmatics of negative questions and tag questions. In Roberta A. Hendrik, Carrie S. Masek \& Mary Frances Miller (eds.), Proceedings of CLS 17, 164-171. Chicago Linguistics Society.

Ladusaw, William. 1979. Polarity sensitivity as inherent scope relations: The University of Texas at Austin PhD dissertation.

van Leusen, Noor. 2004. Incompatibility in context: a diagnosis of correction. Journal of Semantics 21(4). 415-441. https://doi.org/10.1093/jos/21.4.415.

Lewis, David. 1975. Adverbs of quantification. In Edward L. Keenan (ed.), Formal semantics of natural language, 3-15. Cambridge: Cambridge University Press.

Malamud, Sophia \& Tamina Stephenson. 2015. Three ways to avoid commitments: declarative force modifiers in the conversational scoreboard. Journal of Semantics 32. 275-311.

Manzotti, Emilio \& Alessandra Rigamonti. 1991. La negazione. In Lorenzo Renzi \& Giampaolo Salvi (eds.), Grande grammatica italiana di consultazione, 245-317. Bologna: Il Mulino.

Murray, Sarah. 2017. The semantics of evidentials. Oxford University Press. www.doi.org/10.1093/oso/9780199681570.001.0001.

Papafragou, Anna. 2006. Epistemic modality and truth conditions. Lingua 116. 1688-1702. https://doi.org/10.1016/j.lingua.2005.05.009. 
Italian polar questions and 'mica'

Penello, Nicoletta \& Diego Pescarini. 2008. Osservazioni su mica in Italiano e alcuni dialetti veneti. Quaderni di lavoro ASIt 8. 43-56.

Pescarini, Diego. 2009. 'Presuppositional' negation, modality, and the \{addressee . Padua working papers in linguistics 3. 22-28.

Potts, Christopher. 2005. The logic of conventional implicatures. Oxford: Oxford University Press. https://doi.org/doi.org/10.1093/acprof:oso/9780199273829. 001.0001.

Repp, Sophie. 2013. Common ground management: modal particles, illocutionary negation and VERUM. In Daniel Gutzman \& Hans-Martin Gärtner (eds.), Beyond expressives - explorations in use-conditional meaning, 231-274. Emerald Group. https://doi.org/10.1163/9789004183988_008.

Roberts, Craige. 1996. Information structure in discourse: Towards an integrated formal theory of pragmatics, 1998 revision. In Jae Hak Yoon \& Andreas Kathol (eds.), OSUWPL vol. 49: Papers in semantics, The Ohio State University, Department of Linguistics.

Roberts, Craige. 2012. Information structure in discourse: Towards an integrated formal theory of pragmatics. Semantics \& Pragmatics 5(1). 1-69. http://dx.doi. org/10.3765/sp.5.6.

Roelofsen, Floris \& Donka Farkas. 2015. Polarity particle responses as a window onto the interpretation of questions and assertions. Language 91(2). 359-414. https://doi.org/10.1353/lan.2015.0017.

Romero, Maribel. 2014. High negation in subjunctive conditionals and polar questions. In Eva Csipak \& Hedde Zeijlstra (eds.), Proceedings of SuB 19, 499-516.

Romero, Maribel \& Chung-hye Han. 2004. On negative Yes/No questions. Linguistics and Philosophy 27(5). 609-658. https://doi.org/10.1023/B:LING.0000033850. 15705.94.

van Rooy, Robert \& Marie Safarova. 2003. On polar questions. In Robert B. Young \& Yuping Zhou (eds.), Proceedings of SALT 13, 292-309. CLC Publications.

Rullmann, Hotze. 2003. Additive particles and polarity. Journal of Semantics 20. 329-401. https://doi.org/10.1093/jos/20.4.329.

Schwarz, Bernhard \& Rajesh Bhatt. 2006. Light negation and polarity. In Elena Herburger \& Paul Portner (eds.), Cross-linguistic research in syntax and semantics: Negation, tense and clausal architecture, 175-198. Georgetown University Press.

Speas, Peggy \& Carol Tenny. 2003. Configurational properties of point of view roles. In Anna Maria Di Sciullo (ed.), Asymmetry in grammar, 315-344. John Benjamins. https://doi.org/10.1075/la.57.15spe.

Squartini, Mario. 2017. Italian non-canonical negations as modal particles: information state, polarity and mirativity. In Chiara Fedriani \& Andrea Sansó (eds.), Pragmatic markers, discourse markers and modal particles, 203-228. 
Frana \& Rawlins

John Benjamins. https://doi.org/10.1075/slcs.186.08squ.

Stalnaker, Robert. 1978. Assertion. In Peter Cole (ed.), Pragmatics, 315-332. New York: Academic Press.

Sudo, Yasutada. 2013. Biased polar questions in English and Japanese. In Daniel Gutzmann \& Hans-Martin Gärtner (eds.), Beyond expressives: explorations in use-conditional meaning, 275-295. Brill. https://doi.org/10.1163/ 9789004183988_009.

Szabolcsi, Anna. 2004. Positive polarity - negative polarity. Natural Language and Linguistic Theory 22. 409-452. https://doi.org/10.1023/B:NALA.0000015791. 00288.43.

Tonhauser, Judith, David Beaver, Craige Roberts \& Mandy Simons. 2013. Towards a taxonomy of projective content. Language 89(1). 66-109. http://doi.org/10. 1353/lan.2013.0001.

Visconti, Jacqueline. 2009. From "textual" to "interpersonal": on the diachrony of the Italian particle mica. Journal of Pragmatics 41. 937-950. https://doi.org/10. 1016/j.pragma.2008.08.012.

Yuan, Mengxi. 2015. Mandarin discourse adverbs as presupposition triggers: City University of Hong Kong Ph.D. dissertation.

Zanuttini, Raffaella. 1997. Negation and clausal structure: a comparative study of Romance languages. Oxford University Press.

Zimmermann, Malte. 2008. Discourse particles in the left periphery. In Werner Frey, Claudia Maienborn \& Benjamin Shaer (eds.), Dislocation: syntactic, semantic, and discourse perspectives, 200-231. Oxford University Press.

Zimmermann, Malte. 2011. Discourse particles. In Paul Portner, Claudia Maienborn $\&$ Klause von Heusinger (eds.), Semantics: An international handbook of natural language meaning, 2011-2038. Mouton de Gruyter.

Ilaria Frana

Università di Enna "Kore"

Facoltà di Studi Classici, Linguistici

e della Formazione

Viale delle Olimpiadi 1

94100 Enna, Italy

ilaria.frana@unikore.it
Kyle Rawlins

Cognitive Science Department

Johns Hopkins University

3400 N Charles St.

Baltimore, MD, 21218

kgr@jhu.edu 